\title{
La Difusión Enciclopédica de la Psique en América Latina: Diccionarios Para la Enseñanza (1916-2000)
}

\section{The Encyclopedic Dissemination of the Psyche in Latin America: Dictionaries for Teaching (1916-2000)}

\author{
Miguel Gallegos \\ Universidad Católica del Maule \\ Consejo Nacional de Investigaciones Científicas y Técnicas
}

\begin{abstract}
Este trabajo aborda una revisión de los diferentes diccionarios de psicología publicados en América Latina entre 1916 y 2000. Se hizo una recuperación de la información en catálogos editoriales, bases de datos, archivos y bibliotecas, programas de estudios y consultas a especialistas en historia de la psicología. Principalmente se repara en aquellas obras que han alcanzado una difusión masiva en la región. En ese marco, se destacan las obras producidas por autores locales, así como las obras foráneas que fueron traducidas al español y portugués. También se hace referencia a los diversos diccionarios temáticos, tales como los diccionarios de psicología social y de psicoanálisis. En su conjunto, se plantea que la difusión más amplia de los diccionarios en América Latina acontece a partir de mediados del siglo XX, cuando se fundan las carreras de psicología y se cuenta con un público especializado en la materia psicológica.
\end{abstract}

Palabras clave: psicología, diccionarios, historia, América Latina

\begin{abstract}
This paper presents a review of the many dictionaries of psychology published in Latin America between 1916 and 2000. Information was retrieved from publishing house catalogs, databases, archives and libraries, and academic curricula, as well as through consultations with specialists in the history of psychology. The article mainly highlights those works that have become widely disseminated in the region. Within this framework, it foregrounds works produced by local authors, as well as foreign works translated into Spanish and Portuguese. The paper also makes reference to various thematic dictionaries, such as those of social psychology and psychoanalysis. Overall, it is argued that the widest dissemination of dictionaries in Latin America took place after the mid-twentieth century, when universities introduced psychology majors and an audience of psychology specialists had emerged.
\end{abstract}

Keywords: psychology, dictionaries, history, Latin America

Los diccionarios de psicología son un recurso importante para la enseñanza y transmisión de conocimientos, permiten la consulta rápida de alguna cuestión puntual, favorecen el acceso a un público no erudito y evitan divagaciones teóricas en un público informado, entre otras virtudes. También los diccionarios son una herramienta de uso indispensable para la realización de traducciones y precisión terminológica en una lengua diferente a la original. Son parte del acervo conceptual de un campo de conocimiento y, por ello, adquieren el carácter de enciclopedias.

Contextualmente, la aparición de la mayoría de los diccionarios de psicología tiene lugar durante el transcurso del siglo XX, pero su difusión masiva en América Latina acontece cuando se crean los primeros programas de formación en psicología alrededor de la década de 1950: Chile, 1947, Colombia, 1948, Guatemala, 1950, Brasil, 1953, Argentina, 1954, Perú, 1955, Venezuela, 1956 y México, 1959 (Alarcón, 2004; Ardila, 1986; Gallegos, 2009; Klappenbach \& Pavesi, 1994).

Este trabajo se propone describir temáticamente los diccionarios que tuvieron mayor difusión y circulación en los países de América Latina, y con el tiempo se constituyeron en importantes obras de consulta y referencia para la enseñanza de la psicología y la consecuente formación de psicólogos. No se trata de analizar la enseñanza ni la formación en psicología, ya que al respecto existen trabajos especializados

Miguel Gallegos, Universidad Católica del Maule, Talca, Chile, y Consejo Nacional de Investigaciones Científicas y Técnicas, Argentina.

Este trabajo se desarrolló en el marco de una Estancia de Investigación en la Universidad Católica del Maule. También fue posible gracias a un subsidio de la Agencia Nacional de Promoción Científica y Tecnológica de Argentina (Fondo para la Investigación Científica y Tecnológica PICT 2014-2804).

La correspondencia relativa a este artículo debe ser dirigida a Miguel Gallegos, IRICE-CONICET, Bv. 27 de Febrero 210 Bis. 2000 Rosario, Santa Fe, Argentina. E-mail: maypsi@yahoo.com.ar 
(Di Doménico \& Piacente, 2011; Di Doménico \& Vilanova, 1999; Gallegos, 2016; Gallegos \& Berra, 2015; Toro \& Villegas, 2001; Villegas, Marassi \& Toro, 2003a, 2003b), sino de recuperar la historia de esos excelentes recursos pedagógicos que son los diccionarios de psicología, soportes indiscutibles de la enseñanza y transmisión de los conceptos de la disciplina psicológica.

\section{Método}

Metodológicamente, se siguieron las indicaciones técnicas para los estudios históricos de la psicología establecidas por Klappenbach (2014). También se realizó una consulta de fuentes documentales en bibliotecas y archivos históricos en diferentes países de América Latina ${ }^{1}$. En segundo lugar, la información recuperada fue organizada en diferentes cuadros temáticos, indicando el nombre de los autores, el título de las obras, la editorial y el año de publicación. Luego se hizo una categorización de la información para discriminar tres tipos de perfiles de diccionarios: diccionario de psicología, diccionarios temáticos y diccionario de psicoanálisis. En tercer lugar, se procedió al análisis de la información, la cual fue cotejada de acuerdo a diferentes indicadores, con el fin de establecer una medida de la importancia de la obra, su impacto y difusión en América Latina: la disponibilidad de las obras en bibliotecas, la cantidad de reediciones, la cita en diversas asignaturas de introducción a la psicología o de psicología general, las reseñas a las obras y consultas a historiadores de la psicología.

La información recuperada se focalizó en los diccionarios editados durante el siglo XX, específicamente en el período 1916-2000, y cuya difusión logró ser alcanzada por los indicadores mencionados. Por tanto, aun cuando se haga mención a varias obras publicadas durante los últimos años, no se realiza un análisis pormenorizado de las mismas; más bien, se presta especial atención a las obras de mayor antigüedad, dado el carácter histórico que se pretendió esbozar en el trabajo. Un aspecto importante del trabajo se refiere a la inclusión de las obras editadas en portugués, lo cual ha permitido contar con un panorama más completo de la difusión enciclopédica de la psique en América Latina.

\section{Resultados}

\section{Diccionarios de Psicología}

Hasta donde se ha podido indagar, un primer diccionario de psicología, concebido tempranamente y proyectado desde y para la enseñanza de la psicología en tierras latinoamericanas, fue el Diccionario de los Términos Técnicos Usados en Psicología de Francisca Rodríguez, publicado en Argentina en 1916 (Rodríguez, 1916; ver Figura 1). Este diccionario de 149 páginas contiene varios términos de psicología y se basa en la referencia a 119 autores de la psicología. Fue publicado por la editorial Cabut en Buenos Aires. Según informa Víctor Mercante en el prólogo de la obra, se trata de un diccionario gestado durante las labores de enseñanza de la autora en el curso de Psicología, dictado en la Universidad Nacional de La Plata, quien además actuaba como jefa del Laboratorio de Psicología. El propio Mercante (1916) señala que fue una primera referencia que no tuvo antecedentes en idioma español y se concretó al cabo de cinco años de revisión bibliográfica. Cabe recordar que para esa fecha solo se conocía el diccionario de filosofía y psicología editado en inglés por Baldwin (1901, 1902).

\footnotetext{
1 Especial agradecimiento al personal de las siguientes instituciones: Biblioteca de la Facultad de Psicología y Biblioteca de la Facultad de Humanidades y Artes de la Universidad Nacional de Rosario, Argentina; Instituto Rosario de Investigaciones en Ciencias de la Educación, Argentina; Biblioteca de la Facultad de Psicología de la Universidad de Buenos Aires, Argentina; Biblioteca de la Facultad de Psicología, Biblioteca de la Facultad de Filosofía y Letras y Biblioteca Central de la Universidad Nacional Autónoma de México; Biblioteca Nacional de México; Biblioteca Nacional de Guatemala; Biblioteca de la Facultad de Humanidades, Biblioteca Central y Archivo Histórico de la Universidad San Carlos de Guatemala; Biblioteca de la Faculdade de Educação, Biblioteca de la Faculdade de Filosofia e Ciências Humanas y Centro de Documentação e Pesquisa Helena Antipoff de la Universidade Federal de Minas Gerais, Brasil; Biblioteca Nacional de Rio de Janeiro, Brasil; Biblioteca Nacional de Cuba "José Martî"; Biblioteca Central de la Universidad de La Habana "Rubén Martínez Villena”, Cuba; Biblioteca Nacional del Perú; Archivo Central Andrés Bello de la Universidad de Chile; Biblioteca Nacional de Chile.
} 


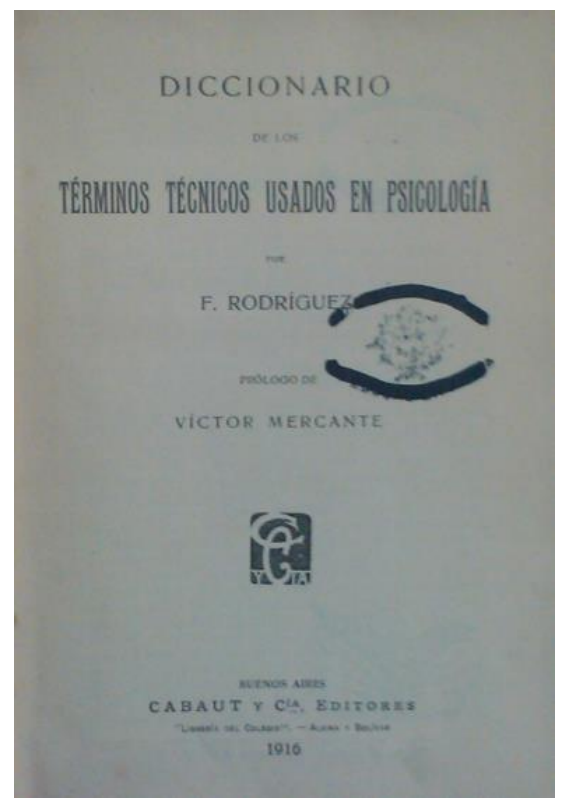

Figura 1. Portada del diccionario de Rodríguez en 1916.

A partir de la década de 1930 comenzarían a publicarse sistemáticamente varios diccionarios de psicología, algunos de los cuales fueron traducidos al castellano y al portugués, aunque muchos otros no corrieron la misma suerte. En la Tabla 1 se pueden observar varios de los diccionarios de psicología editados durante el transcurso del siglo XX.

Tabla 1

Diccionarios de Psicología

\begin{tabular}{|c|c|c|c|}
\hline Autor/es & Título & Editorial & Año \\
\hline Rodríguez & Diccionario de los Términos Técnicos Usados en Psicología & Cabut & 1916 \\
\hline Warren & Diccionario de Psicología & $\begin{array}{l}\text { Fondo de Cultura } \\
\text { Económica }\end{array}$ & 1948 \\
\hline Székely & Diccionario Enciclopédico de la Psique & Claridad & 1950 \\
\hline English & Diccionario Manual de Psicología & El Ateneo & 1951 \\
\hline Pierón & Lexicon Kapelusz Psicología & Kapelusz & 1964 \\
\hline Drever & Diccionario de Psicología & Escuela & 1967 \\
\hline Sillamy & Diccionario de la Psicología & Plaza \& Janés & 1969 \\
\hline Cabral \& Nick & Dicionário Técnico de Psicologia & Cultrix & 1974 \\
\hline Dorsch & Diccionario de Psicología & Herder & 1976 \\
\hline Merani & Diccionario de Psicología & Grijalbo & 1976 \\
\hline Dietrich \& Walter & Vocabulário Fundamental de Psicologia & Edições 70 & 1978 \\
\hline Arnold, Eysenck \& Meili & Diccionario de Psicología & Rioduero & 1979 \\
\hline Gómez Álvarez & Glosario de Psicología (Inglés-Español) & Científico-Técnica & 1985 \\
\hline Braier & Diccionario de Psicología & López Libreros & 1988 \\
\hline Bruno & Diccionario de Términos Psicológicos Fundamentales & Paidós & 1988 \\
\hline Doron \& Parot & Diccionario Akal de Psicología & Akal & 1998 \\
\hline
\end{tabular}

Un trabajo seminal fue realizado por Howard Warren y un equipo de más de 100 colaborares con la edición del Diccionario de Psicología, publicado en inglés en 1934 y luego traducido al castellano en 1948 por la 
editorial Fondo de Cultura Económica de México (Warren, 1934/1998). Dicha obra ha sido reimpresa innumerable veces y todavía se sigue reeditando, al mismo tiempo que sigue siendo una obra de consulta en varios países de la región. Sin temor a equivocaciones, se podría indicar que el diccionario de Warren fue una de las obras más difundidas en América Latina. Además, fue una obra que sirvió de referencia e inspiración a otras de su mismo calibre.

Por su parte, el Diccionario Manual de Psicología de Horace English (1928/1951), quien participó en la obra de Warren, fue originalmente pensado para el uso de los estudios psicológicos en 1928, con el título $A$ Student's Dictionary of Psychological Terms. Posteriormente fue editado en castellano en 1951, sobre la cuarta edición en inglés, por la editorial El Ateneo de Buenos Aires. La versión en castellano cuenta con notas complementarias, ampliación de términos y bibliografía proporcionada por el traductor Oscar Oñativia (1934/1951), quien por esos años no solo fungía como uno de los cultores de la psicología en Argentina, sino además sería uno de los promotores de la creación de las carreras de psicología en el país (Klappenbach, 2006; Rossi, 1994; Rovaletti, 1998).

El Diccionario Enciclopédico de la Psique del húngaro radicado en Argentina, Béla Székely, se convirtió en un clásico de referencia en la materia, no solo en Argentina, país donde se editara, sino también en otros países de la región (Ardila, 1986). Originalmente su primera publicación data de 1950 por la editorial Claridad, con un prólogo de Alfredo Calcagno (1950). Tuvo una segunda reedición en 1958, prologada por Enrique Gandía y complementada por la mujer de Székely, ya que el húngaro había fallecido en 1955, cuando se encontraba rehaciendo la letra T del diccionario (Székely, 1958; ver Figura 2).

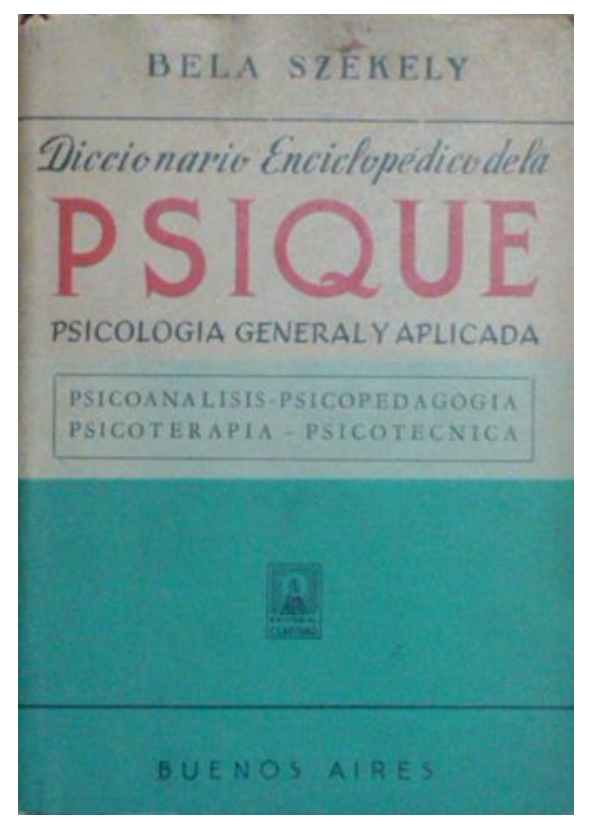

Figura 2. Tapa del diccionario de Székely en 1958.

El diccionario de Székely tuvo innumerables reimpresiones y en la actualidad se sigue editando, aunque en un formato diferente. No obstante, cabe señalar que durante el transcurso de los años fue mutando en su denominación, según las nuevas ediciones, siempre por la editorial Claridad: de Diccionario Enciclopédico de la Psique (Székely, 1950) pasó a llamarse Diccionario de Psicología General y Aplicada, para luego devenir con el simple título de Diccionario de Psicología. Esta última edición fue coordinada por Ricardo Bruno y contó con la colaboración de Héctor Fernández Álvarez y un grupo de autores que revisaron y complementaron la obra (Székely, 2010).

El Diccionario de Psicología de Friedrich Dorsch, que contó con la colaboración de varios autores y coeditores a lo largo de sus múltiples reediciones, fue traducido al castellano por la editorial Herder de 
España. Esta obra tuvo su antecedente en el trabajo de Fritz Giese, Psychologisches Wörterbuch, de 1921, también en alemán, pero con el fallecimiento de su mentor en 1935, la tarea fue continuada por Dorsch (Brožek, 1975; Mankeliunas, 1959). La primera traducción al castellano de 1976 corresponde a la octava edición en alemán (Dorsch, s.i./1976) y la primera publicación en portugués de 2001 por la editorial Vozes corresponde a la onceava en alemán (Dorsch, Häcker \& Stapf, 1987/2004). Aunque el compilador del diccionario falleció en 1987, el diccionario continúa reeditándose y ampliándose sustancialmente, de suerte que se lo concibe como un clásico en la materia.

Entre tanto, el Diccionario de Psicología de James Drever fue editado en inglés por su hijo de nombre homónimo en 1952, luego del fallecimiento de su padre (Pierón, 1957/1964a), y recién en 1967 fue editado en castellano, de acuerdo a la séptima edición en inglés (Drever, 1952/1967). La revisión técnica de la obra estuvo a cargo de Nuria Cortada de Kohan, quien había desempeñado importantes labores de docencia e investigación psicológica en Argentina, además de traducir otras importantes obras psicológicas (Cortada de Kohan, 2012).

El diccionario de Henri Pierón fue publicado en francés en 1951 y luego reeditado en 1957 con una onerosa ampliación, de la cual derivó su traducción al castellano por la editorial Kapelusz en 1964, con un prólogo de Emilio Mira y López (1957/1964), quien señaló la importancia de la obra en la época, en tanto que aportaba a la claridad conceptual en el campo psicológico. Esta obra se conoció como el Lexicón Kapelusz Psicología, en dos tomos o en uno solo, dependiendo de las ediciones que siguieron. Según reconoce el mismo Pierón (1957/1964b), la idea original de proporcionar un vocabulario psicológico se remontaba a 1922, cuando la Sociedad Francesa de Psicología, por iniciativa de Henri Delacroix, propuso una comisión para dicho fin; sin embargo, la comitiva jamás lo llevó a cabo.

Pierón (1957/1964b) reconoció que la obra de Warren no solo fue un modelo a seguir, sino también un texto de gran utilidad para los franceses, pero por el tiempo transcurrido desde su publicación había llegado la hora de proporcionar uno más actualizado. La primera traducción al portugués de este diccionario fue realizada en 1967 y fue reimpresa varias veces por la editorial Globo de Brasil (Pierón, 1957/1977). Posteriormente se hizo una nueva traducción al portugués con base en la cuarta edición francesa (Pierón, 1968/1993), que ya contaba con la colaboración de François Bresson y Gustave Durup, además de incluir un prólogo de Paul Fraisse.

El Diccionario de Psicología del argentino Alberto Merani fue publicado en 1976 y reimpreso varias veces por la editorial Grijalbo de España. La tercera edición (Merani, 1979) fue ampliada y mejorada, aunque conservó la estructura original, la cual disponía de los términos psicológicos, un índice bibliográfico, un glosario de raíces griegas y latinas y un glosario de términos en diversos idiomas, además de un catálogo de obras fundamentales. Si bien en la producción de esta obra puede reconocerse el sesgo y la predilección del autor por la psicología francesa en detrimento de otras, como visiblemente se aprecia respecto de la psicología norteamericana (León, 1979), no obstante, es meritorio reconocer el esfuerzo de sistematización al que se llegó con dicho diccionario. También el autor editó otros diccionarios complementarios, tales como el Diccionario de Pedagogía en 1982 (Merani, 1982), el cual incluía, además de los términos pedagógicos por él seleccionados, un diccionario biográfico y un catálogo de obras contemporáneas referidas a la pedagogía. Otra producción técnica del autor fue el Diccionario de Psicología y Psiquiatría Infantil en 1983 (Merani, 1983).

El trabajo de Norbert Sillamy, Diccionario de la Psicología, original en francés en 1967, fue traducido al español en 1969 (Sillamy, 1967/1974) y por la misma época al portugués. No obstante, la edición original de Larousse en francés también fue publicada por otras editoriales a lo largo del tiempo, de igual forma que las versiones en español de Plaza \& Janés y de la propia editorial Larousse. Incluso el autor fue el coordinador del Dictionnaire Encyclopédique de Psychologie, editado en francés en 1980 por la editorial Bordas. Aquel primigenio diccionario fue un texto pequeño, de consulta breve, pero que tuvo una importante difusión, a juzgar por las diversas traducciones y reimpresiones.

El Diccionario de Psicología, editado en Buenos Aires en 1988 por la editorial López Libreros, estuvo a cargo de León Braier (1988), quien también se comprometió con la recopilación y edición de otros diccionarios afines al campo médico en Argentina. Como dato anecdótico, el diccionario estuvo dedicado a Anna O, lo cual evidencia el perfil psicoanalítico del autor, que él mismo deja en claro en su introducción, al reconocer a Freud, Adler y Jung como los fundadores de una nueva psicología, llamada psicología profunda (Braier, 1988). En esa misma fecha, la editorial Paidós, desde su sede en España, lanzaba la publicación del Diccionario de Términos Psicológicos Fundamentales, original en inglés de 1986, a cargo de Frank Bruno (1986/1997). En dicha obra se expone una ejemplificación de los conceptos psicológicos y la conexión con otros términos del 
vocabulario disciplinar. La editorial Trillas de México editó otra obra del autor, aunque más especializada, Psicología Infantil y Desarrollo: Enciclopedia Familiar, original en inglés de 1992 y primera edición en español de 1995 (Bruno, 1992/1995). La segunda edición de 2005, la cual tuvo varias reimpresiones posteriores, sufrió una modificación en el título: Diccionario de Psicología Infantil (Bruno, 1995/2007). Con esta última denominación se reconoce su más amplia y actualizada difusión.

Desde luego, la edición de diccionarios de la psique en lengua portuguesa no fue menos importante que las editadas en castellano. Muchas de las obras más difundidas en español también fueron traducidas al portugués y tuvieron una importante acogida en los claustros académicos y profesionales vinculados a la psicología en Brasil. Incluso, algunas obras foráneas volcadas al portugués no conocieron traducción al castellano. Para el caso, el Vocabulário Fundamental de Psicologia de Georg Dietrich y Hellmuth Walter, original en alemán de 1970, fue publicado en portugués por la editorial Edições 70 de Lisboa en 1978 (Dietrich \& Walter, 1970/1978) y fue distribuido en Brasil por la librería Martins Fontes.

Otra producción que tuvo una importante divulgación en Brasil fue el Dicionário de Psicologia, en tres tomos, a cargo Wilhelm Arnold, Hans Eysenck y Richard Mieli. La idea de elaborar este diccionario surgió en un encuentro de verano mantenido por los autores y fue planificado para ser editado en seis idiomas. La publicación original en alemán se concibió entre 1971 y 1972 en tres volúmenes por la editorial Herder de Alemania. La primera versión en portugués de 1982 por la editorial Loyola de Brasil fue tomada de la edición de 1976 (Arnold, Eysenck \& Mieli, 1972/1982). La versión en castellano de este diccionario corresponde a la editorial Rioduero de España, publicada en 1979 (Arnold, Eysenck \& Mieli, 1972/1979).

Entre todos estos materiales, hay que referir algunas producciones que, si bien no cumplen con el perfil de un diccionario típico, adquieren gran significación respecto del manejo de los términos psicológicos utilizados en diferentes lenguas. Específicamente, se trata de los glosarios de términos que han sido elaborados con el fin principal de servir a los intérpretes y traductores de obras. Un ejemplo se encuentra en el trabajo de María Gómez Álvarez (1985), con su Glosario de Psicología (Inglés-Español), el cual fue producido y editado en Cuba por la Editorial Científico-Técnica. La aparición de dicho trabajo no resulta azarosa, ya que desde mediados de la década de 1970 se reconocía la preocupación por establecer un tesauro de áreas y temáticas psicológicas en el uso cotidiano de la psicología cubana, en el cual la terminología psicológica pudiera encontrar mayor especificación (Hospital Psiquiátrico de La Habana, 1981).

En los días que corren se siguen produciendo nuevos diccionarios, muchos de los cuales son elaborados por docentes de las carreras de psicología para fines didácticos en las propias labores de enseñanza. Por citar algunos de los editados recientemente en América Latina, el diccionario de Eduardo Cosacov, profesor de la Facultad de Psicología de la Universidad Nacional de Córdoba, Argentina, ya lleva tres ediciones (Cosacov, 2007). La obra de Natalia Consuegra Anaya, editada en Bogotá, Colombia, también cuenta con la segunda reimpresión de una segunda edición (Consuegra, 2011). Por su parte, el argentino Ezequiel Ander-Egg (2012) editó un diccionario de psicología en la editorial Brujas de Córdoba, el cual se suma a otros diccionarios producidos por el autor.

Quizás sorprenda que la sociedad de psicólogos más antigua del mundo, la American Psychological Association (APA), fundada en 1892 y de tanta gravitación en el escenario psicológico internacional, solo muy recientemente editara un diccionario de psicología, aun cuando el propósito de esta labor terminológica estuviera desde sus orígenes. Si bien es cierto que dicha asociación había adquirido los derechos del Dictionary of Psychology and Psychiatry, publicado en 1984 por la editorial Longman, posteriormente comenzó una importante labor editorial con el fin de publicar un diccionario exclusivamente psicológico, el cual fue editado en 2007: el APA Dictionary of Psychology. De aquella edición se tradujo una versión al portugués en 2010 (APA, 2007/2010a) y también se hizo una versión más reducida en inglés por la propia asociación en 2009, la cual fue difundida en español por la editorial El Manual Moderno (APA, 2009/2010b).

La editorial Siglo XXI, con sede en México, publicó en castellano el diccionario en italiano de Galimberti (1992/2002). También hay que mencionar el Diccionario Akal de Psicología, el cual fue producido por Roland Doron y Françoise Parot en francés en 1991, luego traducido y reeditado varias veces desde 1998, tanto en español (Doron \& Parot, 1991/1998a) como en portugués (Doron \& Parot, 1991/1998b). Asimismo, se han editado otros diccionarios con el objetivo de volverse una fuente de consulta actualizada en los términos psicológicos de diferentes ámbitos de actuación profesional (Gregory, 1987/1995; Houdé, Kayser, Koenig, Proust \& Rastier, 1998/2003; Mora \& Sanguinetti, 1994; Stingo, Toro Martínez, Epiño \& Zazzi, 2006). Sin dudas, se podría seguir enumerando la edición de muchos otros diccionarios que han visto la luz últimamente, 
pero la idea del trabajo fue focalizarse en las obras más históricas y en aquellas que han nutrido la enseñanza de la psicología durante el siglo XX en América Latina.

\section{Diccionarios Temáticos}

En el amplio espectro de diccionarios de la psique, también se ha producido y editado un conjunto de diccionarios temáticos, surgidos por la necesidad de dar cabida a la amplitud de campos de especialización de la psicología. Solo a modo ilustrativo se han consignado en la Tabla 2 algunos títulos, con el fin de representar más ampliamente el cuadro de los diccionarios de psicología que se han hecho extensivos desde la diversificación psicológica que se fue propiciando durante la segunda mitad del siglo XX.

Tabla 2

Diccionarios Temáticos de Psicología

\begin{tabular}{|c|c|c|c|}
\hline Autor/es & Título & Editorial & Año \\
\hline Menezes & Dicionário Psico-Pedagógico & $\begin{array}{l}\text { Companhia Editora } \\
\text { Nacional }\end{array}$ & 1935 \\
\hline Valmor & Diccionario de Psicología y Psicoanálisis & Schapire & 1966 \\
\hline Novaes \& Martins & $\begin{array}{l}\text { Glossário de Termos Referentes aos Testes e Medidas } \\
\text { Psicológicas }\end{array}$ & Fundação Getúlio Vargas & 1968 \\
\hline Battro & Diccionario de Epistemología Genética & Proteo & 1971 \\
\hline Alvim & Vocabulário de Termos Psicológicos e Psiquiátricos & $\begin{array}{l}\text { Sociedade Pestalozzi de } \\
\text { Minas Gerais }\end{array}$ & 1971 \\
\hline Cabral & Dicionário de Psicologia e Psicanálise & Expressão e Cultura & 1971 \\
\hline Bastin & Diccionario de Psicología Sexual & Herder & 1972 \\
\hline Campos & Diccionario de Psicología del Aprendizaje & Ciencias de la Conducta & 1974 \\
\hline $\begin{array}{l}\text { Frazier, Campbell, } \\
\text { Marshall \& Werner }\end{array}$ & Terminología Psiquiátrica y de la Clínica Psicológica & Trillas & 1976 \\
\hline Morel \& Moral & Diccionario de Parapsicología & Kier & 1977 \\
\hline English \& English & Diccionario de Psicología y Psicoanálisis & Paidós & 1977 \\
\hline Pereira & Dicionário da Vida Sexual & Abril Cultural & 1981 \\
\hline Merani & Diccionario de Psicología y Psiquiatría Infantil & Grijalbo & 1983 \\
\hline Wolman & Diccionario de Ciencias de la Conducta & Trillas & 1984 \\
\hline Virel & Vocabulario de las Psicoterapias & Gedisa & 1985 \\
\hline Aguirre \& Álvarez & Diccionario de Psicología para Educadores & $\begin{array}{l}\text { Promociones y Publicaciones } \\
\text { Universitarias }\end{array}$ & 1988 \\
\hline Harré \& Lamb & Diccionario de Psicología Fisiológica y Clínica & Paidós & 1990 \\
\hline Harré \& Lamb & Diccionario de Psicología Evolutiva y de la Educación & Paidós & 1990 \\
\hline Harré \& Lamb & Diccionario de Etología y Aprendizaje Animal & Paidós & 1991 \\
\hline Hurtado & Dicionário de Psicomotricidade & Prodil & 1991 \\
\hline Harré \& Lamb & Diccionario de Psicología Social y de la Personalidad & Paidós & 1992 \\
\hline $\begin{array}{l}\text { Menegazzo, Tomasini \& } \\
\text { Zuretti }\end{array}$ & Diccionario de Psicodrama y Sociodrama & Kaicron & 1992 \\
\hline Brunner \& Zeltner & $\begin{array}{l}\text { Dicionário de Psicopedagogia e Psicologia } \\
\text { Educacional }\end{array}$ & Vozes & 1994 \\
\hline Pichon-Rivière & $\begin{array}{l}\text { Diccionario de Términos y Conceptos de Psicología y } \\
\text { Psicología Social }\end{array}$ & Nueva Visión & 1995 \\
\hline Bruno & $\begin{array}{l}\text { Psicología Infantil y Desarrollo: Enciclopedia } \\
\text { Familiar }\end{array}$ & Trillas & 1995 \\
\hline
\end{tabular}

Probablemente, el Dicionário Psico-Pedagogico de Djacir Menezes se encuentre entre las primeras obras realizadas en Brasil con el objetivo de recopilar los conceptos psicológicos con un marcado énfasis pedagógico. Aunque el autor es prácticamente un desconocido en la historia de la psicología brasilera, fue un prolífico escritor de obras de filosofía, literatura, pedagogía, sociología y psicología. Entre ellas, cabe destacar un libro 
didáctico sobre psicología destinado a la enseñanza de la disciplina en las escuelas normales (Menezes, 1933), el cual tuvo varias reediciones con sus respectivas ampliaciones, otro sobre pedagogía (Menezes, 1935a) y el propio diccionario psicopedagógico (Menezes, 1935b; ver Figura 3).

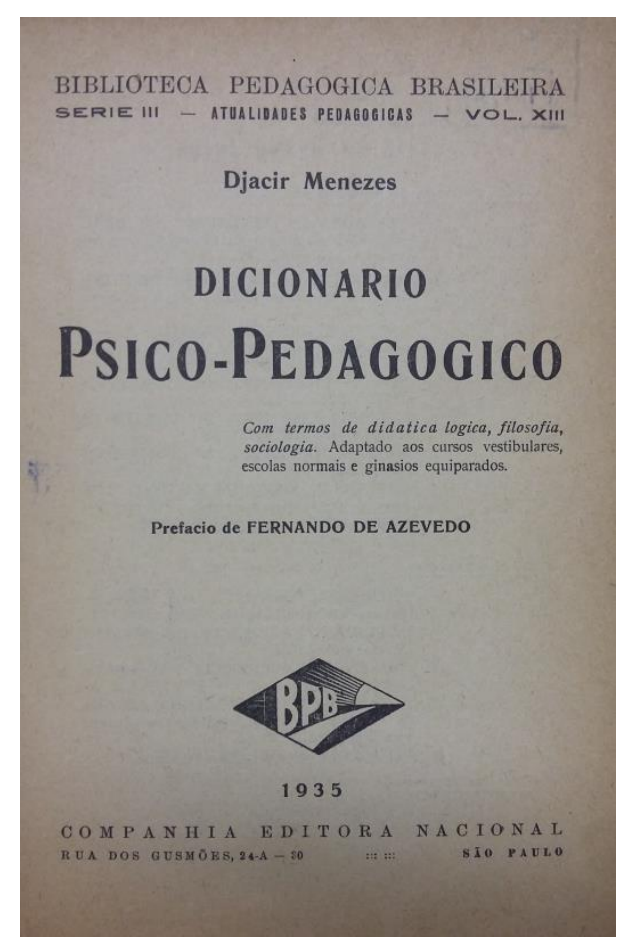

Figura 3. Tapa del diccionario de Menezes en 1935.

El diccionario estuvo prologado por Fernando de Azevedo, reconocido intelectual brasilero, quien por esa época había ocupado diversos cargos académicos y políticos en la administración pública. Además fue el organizador y director de la Biblioteca Pedagógica Brasileira, perteneciente a la Companhia Editora Nacional, donde constaba la sección Actualidades Pedagógicas, en la que se incluía el diccionario referido. En el prólogo se indicaba que la obra era la primera en su especialidad en lengua portuguesa y la misma estaba dirigida a los profesores y educadores de la época, quienes debían proporcionar las sugerencias y críticas para lograr un perfeccionamiento de los conceptos vertidos y, de ese modo, procurar una segunda edición (Azevedo, 1935), la cual no llegó a concretarse.

El Diccionario de Epistemología Genética, del argentino Antonio Battro se publicó originalmente en francés en 1966, con un prólogo de Jean Piaget, luego fue publicado en castellano en 1971 (Battro, 1966/1971) por la editorial Proteo y más tarde se conoció una edición de la editorial Centro Editor Argentino. También fue editado en inglés por la editorial Pergamon en 1973 (Battro, 1966/1973) y posteriormente se conoció una versión en portugués en 1978 por la editorial Pioneira (Battro,1966/1978), cuya publicación fue recomendada por el reconocido profesor de psicología de la Universidade de São Paulo, Dante Moreira Leite (2009), quien, a su vez, tenía agendada la edición de un diccionario de psicología desde 1961 con Maria José de Barros Fornari y Carolina Martucelli Bori, pero no logró concretarse.

Otro de los esfuerzos propios de la región por tratar de concebir una obra que reflejara los conocimientos técnicos de un campo específico fue el Diccionario de Psicología del Aprendizaje, del mexicano Luis Campos (1974). Dicha obra contemplaba el vocabulario de los siguientes campos: análisis experimental de la conducta, condicionamiento clásico, enseñanza programada, metodología, modificación de la conducta, teoría del aprendizaje social y terapia de la conducta. Fue editada en México por la editorial Ciencias de la Conducta. El prólogo de la obra estuvo a cargo de Rubén Ardila (1974a), quien por ese tiempo había organizado la Primera Conferencia Latinoamericana Sobre Entrenamiento en Psicología (Gallegos, 2010a), en Bogotá, Colombia, en 1974, paralelamente al XV Congreso Interamericano de Psicología, del cual fue uno de los 
artífices (Ardila, 1978). Además, fungía como uno de los referentes centrales del movimiento latinoamericano sobre análisis y modificación de la conducta, que en aquellos años lograba institucionalizarse a partir de sociedades científicas, revistas temáticas, congresos y obras especializadas, tales como El Análisis Experimental del Comportamiento: La Contribución Latinoamericana, obra compilada por el propio Ardila (1974b, 1986; Vinaccia, 1978). Precisamente, en dicha obra se incluía un breve glosario de términos psicológicos relacionados con el campo temático del comportamiento (Ardila, 1974b). En el prólogo, Ardila informaba que la Unión Internacional de Psicología Científica, hoy conocida por sus siglas IUPsyS, había publicado un diccionario de psicología, que la Sociedad Interamericana de Psicología (SIP) estaba redactando un diccionario psicológico español-inglés y que el colombiano Mateo Mankeliunas se encontraba elaborando otro diccionario desde hacía varios años. Hoy se sabe que aquel diccionario editado por la IUPsyS en 1975 en rigor consistía en un diccionario trilingüe (inglés, francés y alemán) de términos psicológicos, útil a los fines de las traducciones, y que los diccionarios de la SIP y del psicólogo Mankeliunas nunca llegaron a concretarse.

La aparición de un diccionario especializado en el campo del comportamiento en el ámbito mexicano no es arbitraria, dada la importante influencia que ha tenido dicha corriente psicológica en México. En ese contexto tuvo lugar la publicación del Diccionario de Ciencias de la Conducta, cuya versión original en inglés es de 1973, a cargo de Benjamin Wolman (1975). Fue traducido en 1984 y reimpreso en 1987 por la editorial Trillas de México (Wolman, 1973/1987). La traducción estuvo a cargo de Mario Sandoval Pineda y el responsable de la revisión técnica fue Emilio Ribes Iñesta, reconocido psicólogo interconductista en México.

Tampoco sorprende la edición en Brasil de una obra relacionada con el análisis del comportamiento, puesto que dicha tendencia ha tenido un impacto y desarrollo notorio desde la década de 1970. El Vocabulário de Análise do Comportamento de Rolando Rodrigues Teixeira Jr. y Maria Aparecida Oliveira de Souza (2006), ambos egresados de la Universidade Federal de Minas Gerais, cumplió con el objetivo de disponer en portugués una obra de consulta para estudiantes y profesores interesados en el estudio y la práctica del análisis del comportamiento en Brasil. De la misma manera que varias universidades norteamericanas disponen online sus glosarios de términos en la materia, la obra de los autores brasileros puede consultarse en la página Web de la Faculdade de Filosofia e Ciências Humanas de la mencionada universidad.

Quizás no esté de más recordar aquí una antigua preocupación por la conceptualización en esta área de la psicología en manos de los mexicanos Víctor Colotla y Xochitl Gallegos de Colotla, quienes elaboraron Un Glosario de Términos del Análisis Experimental de la Conducta en el Idioma Español (1971). La propuesta, que incluyó más de 200 entradas, consistió en la traducción de varios términos usuales en el campo de conocimiento referido y fue publicado en formato de artículo en la Revista Latinoamericana de Psicología, una de las más antigua y prestigiosa revista de psicología en la región (Gallegos, 2010b; Gutiérrez, PérezAcosta \& Plata-Caviedes, 2009).

Una obra que, si bien no fue ampliamente recibida en la región, pero que sirvió de consulta en español en el campo de conocimiento de la psicología educativa, fue el Diccionario de Psicología Para Educadores, editado por la editorial Promociones y Publicaciones Universitarias de España en 1988. Dicha obra, editada por Ángel Aguirre y José María Álvarez (1988), en colaboración con un equipo de más de 30 catedráticos españoles, fue el producto de las actividades de enseñanza de la asignatura Psicología de la Educación en la Universidad de Barcelona. Otra obra equivalente en esta temática fue difundida en portugués con el nombre de Dicionário de Psicopedagogia e Psicologia Educacional de Reinhard Brunner y Wolfgang Zeltner. La versión original en alemán data de 1980 y la traducción al portugués recién se conoció en 1994 por la editorial Vozes de Brasil. Tal diccionario ha logrado varias reimpresiones en Brasil (Brunner \& Zeltner, 1980/2004) y, hasta donde se ha tomado conocimiento, no se ha volcado al español.

De las diversas producciones especializadas, cabe referir la publicación del Dicionário de Psicomotricidade, a cargo de Johann Melcherts Hurtado (1991), profesor de varias disciplinas en diversas instituciones de Brasil y otros países de América Latina. La misma fue concebida como parte de las actividades docentes desde la década de 1980 y tuvo como antecedente un glosario elaborado por el propio autor. Se trata de una obra que prácticamente no tiene equivalente, dado que no se conocen muchas obras especializadas en la temática. Por lo demás, hay que destacar que fue una obra elaborada en el propio contexto latinoamericano para actividades didácticas en la universidad.

El Glossário de Termos Referentes aos Testes e Medidas Psicológicas de los autores brasileros Maria Helena Novaes y Octavio Martins (1968), elaborado en 1968 en portugués, se caracteriza por ser una publicación única en la materia. Fue concebido para lograr cierta uniformidad en la nomenclatura relacionada con los test y las medidas psicológicas en el marco de las actividades del Instituto de Seleção e 
Orientação Profissional, de la Fundação Getulio Vargas. De hecho, la pequeña obra de 35 páginas fue publicada con dichos auspicios institucionales y posteriormente fue incorporada como artículo en la reconocida publicación Arquivos Brasileiros de Psicologia Aplicada (Novaes \& Martins, 1969). Cabe recordar que la preocupación por la terminología psicológica, y particularmente en lo atinente a las cuestiones de los test y la psicometría, fue una constante dentro del ámbito de los psicólogos aplicados en Brasil y el resto del mundo (Schneider, 1955).

Por su parte, en 1972 se tradujo del francés el Diccionario de Psicología Sexual de Georges Bastin (1970/1972) por la editorial Herder de España; la versión original fue publicada en 1970. Sin dudas, se trató de una obra pionera en la materia y representó la posibilidad de consulta en español para un público tanto especializado como no especializado. Una obra de similar característica, aunque producida y difundida en portugués, fue el Dicionário da Vida Sexual, de Aldo Pereira (1981), editado en dos tomos en 1981 por la editorial Abril Cultural de Brasil. Otra producción convergente fue el Diccionario de Psicología y Sexología, a cargo de José Luis Olazo García (2003), editado en 2003 en Puebla, México.

El Diccionario de Parapsicología fue reimpreso en tres ocasiones, por lo menos hasta donde se tiene conocimiento, en 1977, 1980 y 1986 por la editorial Kier. En cada oportunidad, sus autores Héctor Morel y José Moral (1986) fueron ampliando la versión, agregando entradas, nuevos capítulos y suplementos. La obra estuvo dedicada a los pioneros de la parapsicología en Argentina, José Fernández, Orlando Canavesio y Ricardo Musso. La inclusión de este diccionario se justifica, porque en algún momento la parapsicología fue incorporada como asignatura y contenido temático en algunos programas de formación en psicología, como en el caso de la primera carrera de psicología en Argentina (Gallegos \& Berra, 2016). Una obra similar en el contexto brasilero se debe a João Teixeira de Paula, quien publicó el Dicionário de parapsicologia, metapsíquica e espiritismo en tres volúmenes (Paula, 1970).

Con el Diccionario de Psicología y Psicoanálisis de Horace English y Ava English comienza a visualizarse con más frecuencia los diccionarios que incluyen el saber psicoanalítico en sus páginas. De hecho, en el prólogo de la misma se justificaba la incorporación de los términos psicoanalíticos, debido al crecimiento exponencial que dicha disciplina había adquirido en los últimos tiempos. La publicación original en inglés data de 1958 (English \& English, 1958), mientras que la edición en español corresponde a 1977 (English \& English, 1958/1977). Los supervisores de la traducción al castellano fueron Jaime Bernstein, Alberto Conesa, Nuria Cortada de Kohan y Hebe Friedenthal. Lo curioso de esta publicación fue la denominación del catálogo de la editorial Paidós donde se incluía la obra: Biblioteca Lexicón Paidós. Tal como se observa, la denominación del catálogo evocaba, de alguna manera, el diccionario de Pierón, editado por Kapelusz dos décadas atrás. Más tarde, la editorial Paidós, desde su sede comercial en España, daría a conocer en la línea editorial "Series Lexicón" una compilación de diccionarios especializados en varios campos de la psicología, a cargo de Rom Harré y Roger Lamb. Tales diccionarios corresponden a The Encyclopedic Dictionary of Psychology, editado en inglés en 1983 (Harré \& Lamb, 1983/1990a, 1983/1990b, 1983/1991, 1983/1992).

Otra obra que también combinó las disciplinas "psi" fue el trabajo de Daniel Valmor, Diccionario de Psicología y Psicoanálisis (Valmor, 1966), editado en Buenos Aires en 1966 por la editorial Schapire. Entre tanto, la obra A Psychiatric Glossary: The Meaning of Terms Frequently Used in Psychiatry, original de 1958 a cargo de la Asociación Psiquiátrica Americana, fue traducida al castellano a partir de su cuarta edición en inglés por la editorial Trillas de México, con el título Terminología Psiquiátrica y de la Clínica Psicológica (Frazier, Campbell, Marshall \& Werner, 1958/1976).

La publicación del Vocabulário de Termos Psicológicos e Psiquiátricos, editado en portugués en 1971 en la ciudad de Belo Horizonte, constituye una de las pocas producciones autóctonas que tuvieron lugar en Brasil y en América Latina en general. Su autor, Clóvis de Faria Alvim, quien fungía como profesor de psiquiatría en la Universidade Federal de Minas Gerais, ideó este diccionario a propósito de la ausencia de obras similares en Brasil, dado que las existentes consistían en traducciones o se encontraban en otras lenguas. Según relata el autor, el glosario de términos había sido concebido varios años atrás por la Sociedad Pestalozzi de Minas Gerais, para que pudiera ser utilizado por estudiantes y profesores, pero por diversas razones no llegó a materializarse hasta la década del 70 (Alvim, 1971). Finalmente fue publicado por la Imprensa Oficial para la Sociedade Pestalozzi de Minas Gerais, siendo una de las 10 mejoras obras producidas en la década de 1970.

Una consideración semejante a la anterior le corresponde al Dicionário de Psicologia e Psicanálise, editado por Álvaro Cabral en 1971 por la editorial Expressão e Cultura de Brasil (Cabral, 1971). Si bien el autor es oriundo de Portugal, donde obtuvo una licenciatura en historia y filosofía en la Faculdade de Letras 
de la Universidade Clássica de Lisboa, y realizó diversos cursos de posgrado en Inglaterra y Alemania, se asentó en Brasil en 1962. Además de escribir varias obras filosóficas, también fue traductor de más de 300 obras de psicología y psicoanálisis. Entre algunos de los autores que tradujo al portugués, pueden citarse a Freud, Jung, Klein, Jones, Piaget, Winnicott, Marcuse y Lazarus. Por su prolífica labor como traductor de literatura psicológica se comprende la inmersión del autor en la edición de un diccionario de términos psicológicos y psicoanalíticos. Hasta donde se tiene conocimiento, tal diccionario tuvo una segunda edición en 1979, revisada y ampliada por el propio autor (Cabral, 1979). Probablemente la aparición del Dicionário Técnico de Psicologia, escrito por el autor en colaboración con Eva Nick en 1974 para la editorial Cultrix de Brasil (Cabral \& Nick, 2006), el cual todavía se sigue publicando con más de 14 ediciones, haya recubierto la necesidad de un vocabulario psicológico especializado en Brasil.

Consecuente con la importancia del trabajo realizado por Enrique Pichon-Rivière en el campo de la psicología social en Argentina, tanto en lo práctico cuanto en lo teórico, hacia 1995 se editó un Diccionario de Términos y Conceptos de Psicología y Psicología Social, que básicamente contemplaba varias de las nociones conceptualizadas por el autor. En este trabajo, Pichon-Rivière es considerado como el fundador de la psicología social en el país y la obra se plantea como un recurso para los estudiantes y profesionales en el campo de la psicología social. Fue compilado por Joaquín Pichon-Rivière (1995), hijo del recordado psicólogo social. En 2002 se editó una obra conexa a la anterior, Diccionario Crítico de Psicología Social: Según la Teoría del Doctor Enrique Pichon-Rivière, a cargo de Leo Rambaut (2002), la cual tuvo una segunda edición en 2007 y una tercera en 2013.

Una obra aledaña al campo psicosocial es el Diccionario de Psicodrama y Sociodrama de los autores Carlos María Menegazzo, Miguel Ángel Tomasini y María Mónica Zuretti. La primera edición de esta obra fue realizada en español en 1992 y posteriormente fue traducida al portugués en 1995 por la editorial Ágora de Brasil, con la cual alcanzaría mayor difusión. Según cuenta uno de los autores, la concepción de esta obra comenzó durante la década de 1960 y se fue gestando con el transcurrir de los años, a medida que se desarrollaba la práctica del psicodrama en Argentina (Menegazzo, 1992/1995). Los mismos autores, unos años más tarde (2012), publicaron otro diccionario temático, Diccionario de Psicodrama, Procedimientos Dramáticos y Socionomía, por la editorial Dunken.

El campo de las psicoterapias no estuvo exento del interés por recopilar varios de los términos más representativos de las diferentes corrientes psicoterapéuticas. A tal efecto, fue concebido el Vocabulario de las Psicoterapias de André Virel, el cual fue publicado en francés en 1977 y posteriormente fue editado en castellano en 1985 por la editorial Gedisa de España. Según el autor, sin desconocer la amplitud del campo de las psicoterapias, en sus páginas se presentan los conceptos de varias escuelas psicológicas y psicoanalíticas, además de otras nociones relacionadas con el aporte de la psicofisiología a la psicoterapia (Virel, 1977/1985).

\section{Diccionarios de Psicoanálisis}

El psicoanálisis, en sus disímiles expresiones, también tuvo sus diversas producciones técnicas en materia de diccionarios. El origen de estas referencias conceptuales se encuentra en Richard Sterba con la publicación en alemán entre 1936 y 1937 del Handwörterbuch der Psychoanalyse en cinco tomos, con una nota manuscrita del propio Freud. La obra quedó inconclusa en la letra L cuando el autor debió emigrar hacia Estados Unidos a raíz de la ocupación nazi en Alemania (de Mijolla, 2002/2005; Lagache, 1967/1996; Roudinesco \& Plon, 1997/1998a).

Durante la década de 1960 comenzarían a publicarse varios diccionarios de psicoanálisis, muchos de los cuales fueron traducidos al castellano y al portugués en los años posteriores. En la Tabla 3 se puede visualizar la mayoría de las producciones psicoanalíticas editadas. Tal vez no resulte accesorio señalar que la mayoría de tales producciones fue concebida en idioma inglés y francés, lo cual puede ser analizado como un indicador de las secuelas de la segunda guerra mundial y el consecuente viraje geopolítico de las instituciones académicas, que pone en evidencia el predominio político del movimiento psicoanalítico, cuyos centros de poder se encontraban esencialmente en Inglaterra y Francia. 
Tabla 3

Diccionarios de Psicoanálisis

\begin{tabular}{|c|c|c|c|}
\hline Autor/es & Título & Editorial & Año \\
\hline Cunha/Fodor \& Gaynor & Dicionário de Termos de Psicanálise de Freud & Globo & 1970 \\
\hline Laplanche \& Pontalis & Diccionario de Psicoanálisis & Labor & 1971 \\
\hline Eidelberg & Enciclopedia del Psicoanálisis & Espaxs & 1971 \\
\hline Doucet & Diccionario del Psicoanálisis Clásico & Labor & 1975 \\
\hline Rycroft & Diccionario de Psicoanálisis & Paidós & 1976 \\
\hline Fedida & Diccionario de Psicoanálisis & Alianza & 1979 \\
\hline Samuels, Shorter \& Plaut & Dicionário Crítico de Análise Junguiana & Imago & 1988 \\
\hline Hinshelwood & Diccionario del Pensamiento Kleiniano & Amorrortu & 1992 \\
\hline Dorgeuille \& Chemama & Dicionário de Psicanálise: Freud \& Lacan & Ágalma & 1994 \\
\hline Sharp & $\begin{array}{l}\text { Lexicon Jungiano: Compendio de Términos y } \\
\text { Conceptos de la Psicología de Carl Gustav Jung }\end{array}$ & Cuatro Vientos & 1994 \\
\hline Valls & Diccionario Freudiano & Julián Yébenes & 1995 \\
\hline Chemama & Dicionário de Psicanálise & Amorrortu & 1995 \\
\hline Kaufmann & Elementos para una Enciclopedia del Psicoanálisis & Paidós & 1996 \\
\hline Hanns & Dicionário Comentado do Alemão de Freud & Imago & 1996 \\
\hline Evans & Diccionario Introductorio de Psicoanálisis Lacaniano & Paidós & 1998 \\
\hline Roudinesco \& Plon & Diccionario de Psicoanálisis & Paidós & 1998 \\
\hline Alarco von Perfall & Diccionario de Psicología Individual & Síntesis & 1999 \\
\hline Hark & $\begin{array}{l}\text { Léxico dos Conceitos Junguianos Fundamentais: A } \\
\text { Partir dos Originais de C. G. Jung }\end{array}$ & Loyola & 2000 \\
\hline Abram & $\begin{array}{l}\text { A Linguagem de Winnicott: Dicionário das Palavras e } \\
\text { Expressões Utilizadas por Donald W. Winnicott }\end{array}$ & Revinter & 2000 \\
\hline
\end{tabular}

El reconocido Vocabulaire de la Psychanalyse de Jean Laplanche y Jean-Bertrand Pontalis, original en francés en 1967 (ver Figura 4), fue traducido al español por la editorial Labor de España en 1971, con sucesivas reimpresiones (Laplanche \& Pontalis, 1967/1979). Posteriormente comenzó a editarse por la editorial Paidós (Laplanche \& Pontalis, 1967/1996), alcanzando una difusión mayor en la parte de habla hispana de Sudamérica. Por su parte, la edición en portugués fue realizada en 1970 por la editorial Moraes de Portugal, luego fue comercializada por la editorial Martins Fontes de Brasil desde 1982 y recién en 1991 se hizo una versión brasilera adaptada al uso corriente del lenguaje en Brasil (Laplanche \& Pontalis, 1967/1988, 1967/2001), en la que participaron varios renombrados psicoanalistas locales. En el prólogo de la obra, redactado por Daniel Lagache (1967/1996), se señala que la misma fue concebida a lo largo de ocho años, luego de un arduo escrutinio sobre los términos psicoanalíticos. Varios de los términos fueron publicados en forma de fascículos en la revista Psyché durante la década de 1950 (de Mijolla, 2002/2005). Asimismo, los autores destacaron la colaboración que prestaron Ángel Garma, Fidias Cesio y Marie Langer para la traducción de los términos en español y Elza Ribeiro Hawelka y Durval Marcondes para los términos en portugués, todos reconocidos psicoanalistas que actuaron en la parte sur de América Latina.

Existe un gran consenso respecto de la importancia de esta obra para el estudio del psicoanálisis y la formación psicoanalítica, tanto por su calidad teórica como por la revisión minuciosa de los conceptos; incluso se lo considera el diccionario más influyente a nivel internacional, dado que el mismo ha sido traducido por lo menos a 15 idiomas diferentes. Sin dudas, esta obra fue una referencia central en los claustros universitarios de psicología, muy utilizada por varias generaciones de estudiantes y todavía lo sigue siendo en diferentes partes del mundo. 


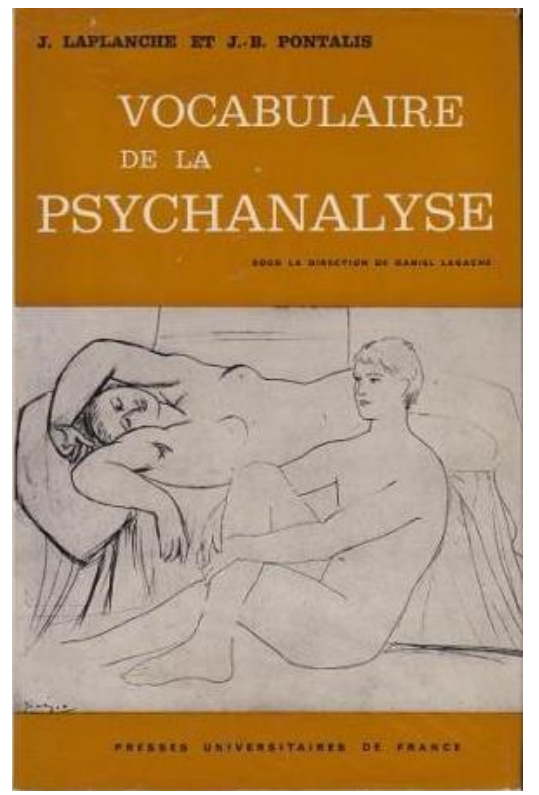

Figura 4. Tapa del diccionario de Laplanche y Pontalis en 1967.

El Diccionario de Psicoanálisis de Charles Rycroft, original en inglés de 1968, inauguró en 1976 el catalogo "Biblioteca Lexicón Paidós" de la editorial homónima (Rycroft, 1968/1976). Según indica el propio autor, su obra es más completa que el vocabulario editado en francés un año antes por Laplanche y Pontalis, ya que proporciona la definición de varios conceptos de otras disciplinas conexas; sin embargo, su obra es mucho más pequeña que su par francés. En la extensa introducción, Rycroft (1968/1976) declara que se trata de una obra basada en el psicoanálisis freudiano, pero no descartó la incorporación de algunos conceptos psicoanalíticos procedentes de otras corrientes, tales como la junguiana, adleriana o existencial.

El Dicionário de Termos de Psicanálise de Freud, cuya edición original en inglés data de 1950, a cargo de Nandor Fodor y Frank Gaynor, con prólogo de Theodor Reik, fue traducido al portugués en 1970 de acuerdo a la edición de 1958, por la editorial Globo de Brasil. La versión brasilera, que no mencionaba a los editores ni incluía el citado prólogo de Reik, estuvo organizada por Jurema Alcides Cunha (1950/1970), quien por ese tiempo actuaba como investigadora asociada a la Universidad de Maryland de Estados Unidos y como profesora de psicología del Instituto de Educação General Flores da Cunha de Porto Alegre, Brasil. Se desconoce una traducción al castellano de este diccionario; seguramente, la aparición de las obras francesas colmó las necesidades del público hispanoparlante.

El Diccionario del Psicoanálisis Clásico, elaborado por Friedrich Doucet en alemán en 1972, fue traducido al castellano en 1975 (Doucet, 1972/1975) por la editorial Labor de España, contando con la revisión técnica del catedrático Antonio Caparrós. Tal como el título de la obra lo sugiere, se trata de abordar los conceptos psicoanalíticos de la mano de los autores referentes del psicoanálisis llamado "clásico": Freud, Adler y Jung. La voluminosa obra compilada por Ludwig Eidelberg, Enciclopedia del Psicoanálisis, fue publicada originalmente en 1968 y posteriormente fue traducida al castellano en España en 1971 (Eidelberg, 1968/1971). Por la envergadura de la obra y la temprana edición en castellano, ha sido una importante obra de consulta para los interesados por el psicoanálisis en tierras iberoamericanas. Por esos años también se editó el Diccionario de Psicoanálisis de Pierre Fedida (1974/1979), cuyo original en francés de 1974 fue publicado por la editorial Larousse.

Tal como han señalado Elisabeth Roudinesco y Michel Plon (1997/1998a), durante los años 90 comenzó a editarse una segunda generación de diccionarios psicoanalíticos que, en su mayoría, irían incorporando la concepción de las diferentes escuelas de psicoanálisis. Si en los años 60 puede situarse una primera oleada de diccionarios psicoanalíticos, desde fines de la década de 1980 comienza otro período de producciones más consecuente con las diferentes expresiones psicoanalíticas. En ese transcurrir se edita el diccionario de los 
propios autores, Diccionario de Psicoanálisis, original en francés de 1997, publicado en castellano por la editorial Paidós de Argentina, y publicado en portugués por la editorial Zahar de Brasil, ambos en 1998 (Roudinesco \& Plon, 1997/1998b, 1997/1998c).

Una producción que también sería prontamente difundida fue Elementos Para una Enciclopedia del Psicoanálisis, original en francés de 1993, cuya compilación estuvo a cargo de Pierre Kaufmann y contó con varios colaboradores. La primera edición en castellano es de 1996 por la editorial Paidós (Kaufmann, 1993/1996a) y la primera versión en portugués también se publica en 1996 por la editorial Zahar (Kaufmann, 1993/1996b). Esta obra se ha convertido en un importante complemento para la revisión de la terminología psicoanalítica y, en especial, para aquella producida en el contexto francés.

La editorial Amorrortu, reconocida por la edición de las obras completas de Freud según la traducción inglesa de James Strachey, editó en castellano el Diccionario de Psicoanálisis en 1998, a cargo de Roland Chemama (1995/1998), cuya versión original en francés comenzó a desarrollarse a principios de la década de 1990 por la editorial Larousse. La versión en portugués se conoció en 1995 por la editorial Artes Médicas (Chemama, 1993/1995). En ambos casos, el diccionario tuvo una segunda edición con la colaboración de Bernard Vandermersch (Chemama \& Vandermersch, 1995/2004), aunque la versión en portugués fue editada por la editorial de la UNISINOS (Chemama \& Vandermersch, 1993/2007). Cabe indicar que Chemama ya se había involucrado en la confección de otro diccionario psicoanalítico una década atrás, Dicionário de Psicanálise: Freud \& Lacan, coordinado por Claude Dorgeuille y Roland Chemama (1984/1994), original en francés de 1984 y publicado en portugués en 1994. En rigor, dicha obra consistió en la compilación de varios artículos teóricos sobre diferentes conceptos psicoanalíticos.

Con todo, el progresivo desarrollo de las diferentes escuelas psicoanalíticas fue responsable de la aparición de diversos diccionarios especializados en la teoría de algunos de los autores más representativos. Por ejemplo, el Diccionario de Psicología Individual, dedicado a la teoría de Alfred Adler, fue editado en castellano por la editorial Síntesis de España en 1999 por Claudio Alarco von Perfall (1999). El Diccionario del Pensamiento Kleiniano, a cargo de Robert Hinshelwood, fue traducido de la versión original en inglés de 1989 unos años más tarde, tanto en español como en portugués (Hinshelwood, 1989/1992a, 1989/1992b). En portugués se editó el Dicionário do Pensamento de Sándor Ferenczi de las psicoanalistas brasileras Haydée Christinne Kahtuni y Gisela Paraná Sanches (2009). Dicha obra se editó únicamente en portugués desde la sede de Elsevier en Brasil (Campus). También en portugués se editó A Linguagem de Winnicott: Dicionário das Palauras e Expressões Utilizadas por Donald W. Winnicott, original en inglés de 1996, a cargo de Jan Abram (1996/2000).

La imponente avanzada del psicoanálisis lacaniano se encontró reflejado en la publicación del Diccionario Introductorio de Psicoanálisis Lacaniano, original en inglés de 1996, a cargo de Dylan Evans. Fue traducido dos años más tarde al castellano por la editorial Paidós, con varias reimpresiones sucesivas (Evans, 1996/2007). Si bien la mayoría de los nuevos diccionarios psicoanalíticos, principalmente aquellos que son elaborados por autores franceses, incluyen la terminología lacaniana en sus páginas, este diccionario se ha especializado en la conceptualización teórica proporcionada por Jacques Lacan. Es probable que en el futuro sigan apareciendo las obras especializadas en el vocabulario lacaniano, ya que se trata de un autor contemporáneo que sigue siendo objeto de un profundo estudio por parte de la comunidad psicoanalítica.

Entre todas estas obras especializadas en cierta corriente psicoanalítica, hay que abrir un paréntesis para destacar la prolífica producción de diccionarios destinados a la teoría de Carl Gustav Jung. El Dicionário Crítico de Análise Junguiana de Andrew Samuels, Bani Shorter y Fred Plaut, original en inglés de 1986, fue traducido al portugués en 1988 por la editorial Imago de Brasil (Samuels, Shorter \& Plaut, 1986/1988); se desconoce una versión en español de esta obra. Otra producción en esta línea se debe Helmut Hark con su Léxico dos Conceitos Junguianos Fundamentais: A Partir dos Originais de C. G. Jung, la cual fue producida en alemán en 1988 y luego volcada al portugués en 2000 (Hark, 1988/2000). Hasta donde se sabe, tampoco fue editada en español.

Lo mismo acontece con el Dicionário Junguiano de Paolo Francesco Pieri (1992/2002), el cual fue traducido del original italiano de 1992 al portugués por la editorial Vozes de Brasil. El Lexicon Jungiano: Compendio de Términos y Conceptos de la Psicología de Carl Gustav Jung de Daryl Sharp fue publicado originalmente en inglés en 1991 y luego fue publicado en castellano en 1994 por la editorial Cuatro Vientos de Chile (Sharp, 1991/1994). Nuevamente, el peruano Claudio Alarco von Perfall (2011) fue responsable del Diccionario de la Psicología de C. G. Jung, editado por la editorial de la Universidad San Martín de Porres. 
El mismo autor, además del diccionario referido anteriormente, ya tenía publicado un Diccionario Práctico para el Conocimiento Sexual (Alarco von Perfall, 2009).

Entre tanto, la necesidad de justeza y precisión terminológica en psicoanálisis también dio lugar a la edición de un diccionario sobre conceptos originales en alemán, como el Dicionário Comentado do Alemão de Freud, original en portugués de Luiz Alberto Hanns (1996) y cuya traducción al castellano fue realizada en 2001 por las editoriales Lohlé y Lumen (Hanns, 1996/2001). La aparición de esta obra no solo refleja el pronunciado interés por la correcta utilización de la terminología psicoanalítica, sino además corrobora esa vieja preocupación que ha existido siempre respecto de la traducción a otros idiomas de los conceptos freudianos originales en alemán.

El Vocabulário Contemporâneo de Psicanálise del psicoanalista brasilero David Zimerman (2001) se encuentra entre las pocas obras en la materia realizadas en el propio terreno latinoamericano. Desde luego, no sorprende dicha producción, dado que el psicoanálisis ha tenido un impacto insoslayable en la porción sur del continente americano. La misma consideración puede hacerse respecto del Diccionario Freudiano del argentino José Luis Valls (1995). Mientras que la obra del brasilero contempla el amplio espectro de la conceptualización psicoanalítica, en particular contemporánea, la obra del argentino se especializa en la terminología freudiana, tal como el título de la obra lo pone de manifiesto. En este conjunto de obras autóctonas conviene destacar la elaboración del Glosario de Términos Lacanianos de Albano, Levit y Gardner (2005), que ha tenido una importante difusión en Argentina. Varios de los autores involucrados en esta producción también se han comprometido con la elaboración de otros diccionarios afines (Albano, 2007; Albano, Levit \& Rosenberg, 2005).

Una mención especial merece el Diccionario de Psicoanálisis Argentino, editado por la Asociación Psicoanalítica Argentina (Borensztejn, 2014). El mismo fue concebido hace muchos años atrás; incluso la formulación de un Tesauro de Psicoanálisis por dicha asociación en la década de 1980 fue un paso decisivo en la elaboración del diccionario. La aparición de esta obra no es casual en un país donde se encuentra una amplia trayectoria de las ideas freudianas y donde se propició un fuerte proceso de institucionalización psicoanalítica, el cual tuvo un impacto considerable en varios países de la región (Cesio, 1981; Rascovsky \& Rosenthal, 1947). Se trata de una obra que contiene la referencia a varios términos psicoanalíticos producidos por autores argentinos, es decir, no contempla la mayoría de los términos psicoanalíticos concebidos, sino más bien apunta a destacar la originalidad conceptual pergeñada por los psicoanalistas que actuaron en el país. Se puede revisar la noción de psiquismo fetal de Rascovsky, la contratransferencia concordante y complementaria de Racker, la comunicación de Liberman y la hora de juego diagnóstica de Aberastury, entre otras (Borensztejn, 2014).

Recientemente se ha editado en portugués el Dicionário Internacional da Psicanálise, dirigido por Alain de Mijolla (2002/2005). La versión original en francés corresponde al año 2002, luego tuvo una edición en inglés en 2005 y en español fue traducido en 2008 como Diccionario Akal Internacional de Psicoanálisis. Se trata de una obra colectiva en la que participaron varios psicoanalistas y contiene alrededor de 2000 páginas. La obra fue elaborada durante varios años y contó con el asesoramiento de la Asociación Internacional de Historia del Psicoanálisis.

Estos materiales son tan solo una muestra de los diccionarios "psi" que tuvieron difusión en los países de la región, donde algunos fueron más consultados que otros y varios de ellos han sido ampliamente utilizados e incorporados en la enseñanza y la formación en psicología. Un balance general de todas estas publicaciones indica, por lo menos para ciertos países con mayor tradición psicoanalítica, el flagrante desplazamiento de la producción y el comercio de diccionarios de psicología por la edición de diccionarios de psicoanálisis o de diccionarios que combinan la psicología y el psicoanálisis. Desde luego, esto no quiere decir que los diccionarios de psicología no se siguieran produciendo y editando, pero es evidente que la producción de los diccionarios psicoanalíticos también ha sido prolífica, con mayor evidencia en aquellos países que cuentan con una profusa difusión del psicoanálisis en el ámbito universitario.

\section{Consideraciones Finales}

De acuerdo a lo esbozado en el desarrollo del trabajo, es indudable que la edición de diccionarios psicológicos ha sido prolífica y diversa. La mayoría de las obras producidas reconoce un origen foráneo, aunque con su consecuente traducción al español y al portugués. Por supuesto que algunos diccionarios de referencia a nivel internacional no fueron traducidos ni al castellano ni al portugués, pero la mayoría de las 
obras más importante en la materia tuvo una amplia difusión en suelo latinoamericano. Algunas obras traducidas al castellano producidas en España no alcanzaron una difusión mayor en los países de América Latina, pero, desde luego, existieron y fueron diversas. Les tocará a los historiadores de la psicología española ofrecer un trabajo sobre esta materia; aquí solamente se reparó en aquellas obras que tuvieron un alcance latinoamericano.

No es menor el esfuerzo realizado por los autores latinoamericanos, ya que se ha podido constatar una importante cantidad de obras elaboradas por autores locales, tanto en lo concerniente a diccionarios generales como en lo relativo a diccionarios especializados en algún área de la disciplina. Además, numerosas traducciones de obras extranjeras al castellano y al portugués contaron con la asistencia técnica de importantes figuras de la psicología y el psicoanálisis en América Latina, algunas de las cuales se desempeñaron en las actividades de enseñanza y formación en psicología. Precisamente, la inspiración para editar este tipo de obras, tan técnicas y especializadas, se debe a la necesidad de contar con recursos didácticos que permitan facilitar la enseñanza, comprensión y transmisión de los conocimientos psicológicos.

Las editoriales locales, es decir, aquellas que han sido fundadas en suelo latinoamericano, también fueron importantes protagonistas de esta historia enciclopédica. En efecto, editoriales como Paidós de Argentina, Vozes de Brasil y Trillas y Fondo de Cultura Económica de México no solo fueron relevantes en la publicación de diccionarios, sino más ampliamente de material psicológico. Entre las editoriales con sede en España se destacan Herder y Labor, aunque también Alianza. La editorial Larousse ha sido una editorial especializada en la publicación de diversos diccionarios y, por tanto, no es cual que se la encuentre muy referenciada en el ámbito de la producción de diccionarios psicológicos.

Si durante la primera mitad del siglo XX la producción de diccionario fue más bien exigua, con la creación de las carreras de psicología y el consecuente despliegue de la enseñanza y formación en psicología, la producción de los mismos fue mucho más pronunciada y diversa. Varios de los diccionarios editados durante los años 50 y 60 del siglo XX expusieron las condiciones disciplinarias en las que se situaba la psicología de entonces, donde cada teoría psicológica o autor de referencia empleaba diversos conceptos de acuerdo a su parecer, todo lo cual se prestaba a una gran confusión terminológica. La necesidad de una claridad conceptual y, más aún, la búsqueda de una unificación terminológica, como clave para lograr ciertos consensos entre los destinatarios del lenguaje psicológico, conjuntamente con las necesidades de la enseñanza, fueron parte del pretexto para la construcción y elaboración de los diccionarios de la psique. Es notoria la proliferación de los diccionarios temáticos a partir de la década de 1970, lo cual denota la progresiva especialización de las diferentes áreas del quehacer psicológico. El impacto de dicha especialización se tradujo en importantes esfuerzos didácticos por aglutinar los conceptos específicos para su transmisión y enseñanza, así como para la consulta de los propios profesionales que laboran en el área de especialidad.

No es casual que la difusión más amplia de los diccionarios se encuentre a partir de la mitad del siglo XX en América Latina, luego de la organización de las carreras de psicología en la región. En efecto, la proliferación masiva de diccionarios acontece desde el momento en el que se crean las condiciones para la enseñanza y la formación en psicología. Antes de ese período, si bien se habían registrado algunas publicaciones locales y algunas escasas traducciones, lo cierto es que la proliferación de los diccionarios acontece cuando se crea un público especializado como destinatario. En este caso, los destinatarios predilectos serían los estudiantes, aunque también los profesores y los investigadores de la materia psicológica. A partir de entonces, la producción de enciclopedias de la psique siguió una marcha ascendente que no parece tener límites, ya que el propio dinamismo disciplinar y la diversidad de ámbitos de actuación, que cada vez tiende a ensancharse más, hacen de la psicología un campo en constante crecimiento y, por ende, un terreno en constante tensión terminológica y búsqueda de claridad conceptual, todo lo cual conlleva a la producción de diccionarios de la psique.

\section{Referencias}

Abram, J. (1996/2000). A linguagem de Winnicott: dicionário das palavras e expressões utilizadas por Donald W. Winnicott [El lenguaje de Winnicott: diccionario de palabras y expresiones utilizadas por Donald W. Winnicott] (M. Del Grande da Silva, Trad.; Título original: The language of Winnicott: A dictionary of Winnicott's use of words). Rio de Janeiro, Brasil: Revinter.

Aguirre, Á. \& Álvarez, J. M. (Eds.) (1988). Diccionario de psicología para educadores. Barcelona, España: Promociones y Publicaciones Universitarias.

Alarco von Perfall, C. (1999). Diccionario de psicología individual. Madrid, España: Síntesis.

Alarco von Perfall, C. (2009). Diccionario práctico para el conocimiento sexual. Barcelona, España: Ediciones 29.

Alarco von Perfall, C. (2011). Diccionario de la psicología de C. G. Jung. Lima, Perú: Editorial Universidad San Martín de Porres. 
Alarcón, R. (2004). Medio siglo de psicología latinoamericana: una visión de conjunto. Revista Interamericana de Psicología/Interamerican Journal of Psychology, 38, 307-316.

Albano, S. (2007). Michel Foucault: glosario epistemológico. Buenos Aires, Argentina: Quadrata.

Albano, S., Levit, A. \& Gardner, H. (2005). Glosario de términos lacanianos. Buenos Aires, Argentina: Quadrata.

Albano, S., Levit, A. \& Rosenberg, L. (2005). Diccionario de semiótica (2ª ed.). Buenos Aires, Argentina: Quadrata.

Alvim, C. F. (1971). Vocabulário de termos psicológicos e psiquiátricos [Vocabulario de términos psicológicos y psiquiátricos]. Belo Horizonte, Brasil: Sociedade Pestalozzi de Minas Gerais.

American Psychological Association (2007/2010a). Dicionário de psicologia [Diccionario de psicología] (D. Bueno, M. A. V. Veronese \& M. C. Monteiro, Trads.; Título original: APA dictionary of psychology). Porto Alegre, Brasil: Artmed.

American Psychological Association (2009/2010b). APA diccionario conciso de psicología (J. L. Núñez Herrejón \& M. E. Ortiz Salinas, Trads.; Título original: APA concise dictionary of psychology). México DF, México: Manual Moderno.

Ander-Egg, E. (2012). Diccionario de psicología. Córdoba, Argentina: Brujas.

Ardila, R. (1974a). Prólogo. En L. F. Campos, Diccionario de psicología del aprendizaje (pp. 5-6). México DF, México: Editorial Ciencias de la Conducta.

Ardila, R. (Ed.) (1974b). El análisis experimental del comportamiento: la contribución latinoamericana. México DF, México: Trillas.

Ardila, R. (Ed.) (1978). La profesión del psicólogo. México DF, México: Trillas.

Ardila, R. (1986). La psicología en América Latina: pasado, presente y futuro. México DF, México: Siglo XXI.

Arnold, W., Eysenck, H. J. \& Mieli, R. (1972/1979). Diccionario de psicología (M. M. Álvarez de Toledo y Morenés \& A. Rodero Carrasco, Trads.; Título original: Lexicon der Psychologie). Madrid, España: Rioduero.

Arnold, W., Eysenck, H. J. \& Mieli, R. (1972/1982). Dicionário de psicologia [Diccionario de psicología] (W. Valle Martins, Trad.; Título original: Lexicon der Psychologie). São Paulo, Brasil: Loyola.

Azevedo, F. (1935). Duas palavras [Dos palabras]. En D. Menezes, Dicionário psico-pedagógico [Diccionario psico-pedagógico] (pp. 7-9). São Paulo, Brasil: Companhia Editora Nacional.

Baldwin, J. M. (1901). Dictionary of philosophy and psychology (Vol. I). New York, NY: Macmillan.

Baldwin, J. M. (1902). Dictionary of philosophy and psychology (Vol. II). New York, NY: Macmillan.

Bastin, G. (1970/1972). Diccionario de psicología sexual (J. Pombo, Trad.; Título original: Dictionnaire de la psychologie sexuelle). Barcelona, España: Herder.

Battro, A. M. (1966/1971). Diccionario de epistemología genética (A. Battro, Trad.; Título original: Dictionnaire d'épistémologie génétique). Buenos Aires, Argentina: Proteo.

Battro, A. M. (1966/1973). Piaget: Dictionary of terms (E. Rütschi-Herrmann \& S. Campbell, Trads.; Título original: Dictionnaire d'épistémologie génétique). New York, NY: Pergamon Press.

Battro, A. M. (1966/1978). Dicionário terminológico de Jean Piaget [Diccionario de términos de Jean Piaget] (L. de Macedo, Trad.; Título original: Dictionnaire d'épistémologie génétique). São Paulo, Brasil: Pioneira.

Borensztejn, C. L. (Coord.) (2014). Diccionario de psicoanálisis argentino. Buenos Aires, Argentina: Asociación Psicoanalítica Argentina.

Braier, L. (1988). Diccionario de psicología. Buenos Aires, Argentina: López Libreros.

Brožek, J. (1975). Contemporary West European historiography of psychology. History of Science, 13, 29-60. https://doi.org/10.1177/007327537501300102

Brunner, R. \& Zeltner, W. (1980/2004). Dicionário de psicopedagogia e psicologia educacional [Diccionario de psicopedagogía y psicología educacional] ( $4^{\mathrm{a}}$ ed.; C. Gomes, Trad.; Título original: Lexikon zur pädagogischen Psychologie und Schulpädagogik). Petrópolis, Brasil: Vozes.

Bruno, F. J. (1986/1997). Diccionario de términos psicológicos fundamentales (2 $2^{\mathrm{a}}$ ed.; L. Wolfson, Trad.; Título original: Dictionary of key words in psychology). Barcelona, España: Paidós.

Bruno, F. J. (1992/1995). Psicología infantil y desarrollo: enciclopedia familiar (M. E. Moreno, Trad.; Título original: The family encyclopedia of child psychology and development). México DF, México: Trillas.

Bruno, F. J. (1995/2007). Diccionario de psicología infantil (Reimpresión de la $2^{\text {a }}$ ed.; M. E. Moreno, Trad.; Título original: The family encyclopedia of child psychology and development). México DF, México: Trillas.

Cabral, A. (1971). Dicionário de psicologia e psicanálise [Diccionario de psicología y psicoanálisis]. Rio de Janeiro, Brasil: Expressão e Cultura.

Cabral, A. (1979). Dicionário de psicologia e psicanálise [Diccionario de psicología y psicoanálisis] (2a ed.). Rio de Janeiro, Brasil: Expressão e Cultura.

Cabral, A. \& Nick, E. (2006). Dicionário técnico de psicologia [Diccionario técnico de psicología] (14ª ed.). São Paulo, Brasil: Cultrix.

Calcagno, A. (1950). Prólogo. En B. Székely, Diccionario enciclopédico de la psique: psicología general y aplicada (pp. 2-12). Buenos Aires, Argentina: Claridad.

Campos, L. F. (1974). Diccionario de psicología del aprendizaje. México DF, México: Editorial Ciencias de la Conducta.

Cesio, F. (1981). Historia del movimiento psicoanalítico latinoamericano. Revista de Psicoanálisis, 38, 695-713.

Chemama, R. (Org.) (1993/1995). Dicionário de psicanálise [Diccionario de psicoanálisis] (F. Franke Settineri, Trad.; Título original: Dictionnaire de la psychanalyse). Porto Alegre, Brasil: Artes Médicas.

Chemama, R. (Dir.) (1995/1998). Diccionario del psicoanálisis (T. P. Lecman, Trad.; Título original: Dictionnaire de la psychanalyse). Buenos Aires, Argentina: Amorrortu.

Chemama, R. \& Vandermersch, B. (1995/2004). Diccionario del psicoanálisis (2ª ed.; T. P. Lecman \& I. Agoff, Trads.; Título original: Dictionnaire de la psychanalyse). Buenos Aires, Argentina: Amorrurtu.

Chemama, R. \& Vandermersch, B. (1993/2007). Dicionário de psicanálise [Diccionario de psicoanálisis] (F. Franke Settineri \& M. Fleig, Trads.; Título original: Dictionnaire de la psychanalyse). São Leopoldo, Brasil: UNISINOS.

Colotla, V. A. \& Gallegos de Colotla, X. (1971). Un glosario de términos del análisis experimental de la conducta en el idioma español. Revista Latinoamericana de Psicología, 3, 37-50.

Consuegra Anaya, N. (2011). Diccionario de psicología (2 $2^{\mathrm{a}}$ ed., $2^{\mathrm{a}}$ Reimpresión). Bogotá, Colombia: ECOE.

Cortada de Kohan, N. (2012). Autobiografía. En H. Klappenbach \& R. León (Eds.), Historia de la psicología iberoamericana en autobiografías (pp. 192-208). Lima, Perú: Sociedad Interamericana de Psicología/Editorial Universidad Ricardo Palma.

Cosacov, E. (2007). Diccionario de términos técnicos de la psicología (3ª ed.). Córdoba, Argentina: Brujas. 
Cunha, J. A. (1950/1970). Introdução [Introducción]. En J. A. Cunha (Org.), Dicionário de termos de psicanálise de Freud [Diccionario de términos psicoanalíticos de Freud] (pp. IX-XII; J. Alcides Cunha, Trad.; Título original: Freud: Dictionary of psychoanalysis). Porto Alegre, Brasil: Globo.

de Mijolla, A. (Dir.) (2002/2005). Dicionário internacional da psicanálise: conceitos, noções, biografias, obras, eventos, instituições [Diccionario internacional de psicoanálisis: conceptos, nociones, biografías, obras, acontecimientos, instituciones] (A. Cabral, Trad.; Título original: Dictionnaire international de la psychanalyse - Concepts, notions, biographies, œuvres, événements, institutions). Rio de Janeiro, Brasil: Imago.

Di Doménico, C. \& Piacente, T. (2011). Acreditación en psicología en el Cono Sur de América. Psicolatina, 22, 1-18.

Di Doménico, C. \& Vilanova, A. (Eds.) (1999). Formación de psicólogos en el Mercosur. Mar del Plata, Argentina: Universidad Nacional de Mar del Plata.

Dietrich, G. \& Walter, H. (1970/1978). Vocabulário fundamental de psicologia [Vocabulario fundamental de psicología] (A. Morão, Trad.; Título original: Grundbegriffe der psychologischen Fachsprache). Lisboa, Portugal: Edições 70.

Dorgeuille, C. \& Chemama, R. (Eds.) (1984/1994). Dicionário de psicanálise: Freud \& Lacan 1 [Diccionario de psicoanálisis: Freud y Lacan 1] (L. M. Fischer Bernardino, C. Cardoso, I. Corrêa, N. C. Irusta, D. de Oliveira Lima, J. Kondera Mengarelli ... R. Vaillati, Trads.; Títulos originales: 15 obras de 1984 a 1993). Salvador, Brasil: Ágalma.

Doron, R. \& Parot, F. (1991/1998a). Diccionario Akal de psicología (B. J. Fabregoul \& A. Arbesú Castañón, Trads.; Título original: Dictionnaire de psychologie). Madrid, España: Akal.

Doron, R. \& Parot, F. (1991/1998b). Dicionário de psicologia [Diccionario de psicología] (O. Soares, Trad., Título original: Dictionnaire de psychologie). São Paulo, Brasil: Ática.

Dorsch, F. (s.i./1976). Diccionario de psicología (I. Antich, Trad.; Título original: Psychologisches Wörterbuch). Barcelona, España: Herder.

Dorsch, F., Häcker, H. \& Stapf, K. H. (1987/2004). Dicionário de psicologia [Diccionario de psicología] (2a ed.; E. Carneiro Leão et al., Trads.; Título original: Dorsch psychologisches Wörterbuch). Petrópolis, Brasil: Vozes.

Doucet, F. W. (1972/1975). Diccionario del psicoanálisis clásico (A. Caparrós, Trad.; Título original: Psychoanalytische Begriffe). Barcelona, España: Labor.

Drever, J. (1952/1967). Diccionario de psicología (A. Bonanno, Trad.; Título original: A dictionary of psychology). Buenos Aires, Argentina: Editorial Escuela.

Eidelberg, L. (1968/1971). Enciclopedia del psicoanálisis (V. Hernández Espinosa, P. Folch Mateu \& S. Adroer Tasis, Trads.; Título original: Encyclopedia of psychoanalysis). Barcelona, España: Espaxs.

English, H. B. (1928/1951). Diccionario manual de psicología (O. Oñativia, Trad.; Título original: A student's dictionary of psychological terms). Buenos Aires, Argentina: El Ateneo.

English, H. B. \& English, A. C. (1958). A comprehensive dictionary of psychological and psychoanalytical terms. New York, NY: Longmans Green.

English, H. B. \& English, A. C. (1958/1977). Diccionario de psicología y psicoanálisis (M. Brea, S. Igon, E. Mendolía \& A. Shor, Trads.; Título original: A comprehensive dictionary of psychological and psychoanalytical terms). Buenos Aires, Argentina: Paidós.

Evans, D. (1996/2007). Diccionario introductorio de psicoanálisis lacaniano (4 Reimpresión; J. Piatigorsky, Trad.; Título original: An introductory dictionary of Lacanian psychoanalysis). Buenos Aires, Argentina: Paidós.

Fedida, P. (1974/1979). Diccionario de psicoanálisis (G. Perucchi, Trad.; Título original: Dictionnaire de la psychanalyse). Madrid, España: Alianza.

Frazier, S. H., Campbell, R. J., Marshall, M. H. \& Werner, A. (1958/1976). Terminología psiquiátrica y de la clínica psicológica (J. Salazar Quevedo, E. Herrada Barrera \& D. González, Trads.; Título original: A psychiatric glossary: The meaning of terms frequently used in psychiatry). México DF, México: Trillas.

Galimberti, U. (1992/2002). Diccionario de psicología (M. E. de Quevedo, Trad.; Título original: Dizionario di psicología). México DF, México: Siglo XXI.

Gallegos, M. (2009). Movimiento y participación estudiantil en la psicología latinoamericana: consideraciones históricas y futuras perspectivas. Avances en Psicología Latinoamericana, 27, 33-60.

Gallegos, M. (2010a). La Primera Conferencia Latinoamericana Sobre Entrenamiento en Psicología (1974): el modelo latinoamericano y su significación histórica. Psicologia: Ciência e Profissão, 30, 792-809. https://doi.org/10.1590/S1414-98932010000400010

Gallegos, M. (2010b). La Revista Latinoamericana de Psicología en sus 40 años de historia: 1969-2009. Universitas Psychologica, 9, $911-924$.

Gallegos, M. (2016). Historia de la psicología y formación en psicología en América Latina: convergencias temáticas. Enseñanza e Investigación en Psicología, 21, 319-335.

Gallegos, M. \& Berra, M. (2015). La preocupación por la formación de psicólogos en América Latina: una revisión histórica. Revista Peruana de Historia de la Psicología, 1, 107-118.

Gallegos, M. \& Berra, M. (2016). Los orígenes de la formación académica de psicólogos en Argentina: la primera carrera de psicología en Rosario. En R. E. Mardones Barrera (Ed.), Historia local de la psicología: discusiones teóricas, metodológicas y experiencias de investigación (pp. 303-351). Santiago, Chile: Ediciones Universidad Santo Tomás.

Gómez Álvarez, M. (1985). Glosario de psicología (inglés-español). La Habana, Cuba: Editorial Científico-Técnica.

Gregory, R. L. (Ed.) (1987/1995). Diccionario Oxford de la mente (I. Cifuentes de Castro, C. Siguenza Pinilla, C. Sender Fernández, T. Amo \& J. Cordero, Trads.; Título original: The Oxford companion to the mind). Madrid, España: Alianza.

Gutiérrez, G., Pérez-Acosta, A. M. \& Plata-Caviedes, T. (2009). Desarrollo histórico de una publicación científica: cuarenta años de la Revista Latinoamericana de Psicología. Revista Latinoamericana de Psicología, 41, 413-428.

Hanns, L. A. (1996). Dicionário comentado do alemão de Freud [Diccionario comentado del alemán de Freud]. Rio de Janeiro, Brasil: Imago.

Hanns, L. A. (1996/2001). Diccionario de términos alemanes de Freud (S. E. Hassan, Trad.; Título original: Dicionário comentado do alemão de Freud). Buenos Aires, Argentina: Lohlé/Lumen.

Hark, H. (1988/2000). Léxico dos conceitos junguianos fundamentais: a partir dos originais de C. G. Jung [Léxico de los conceptos junguianos fundamentales: a partir de los originales de C. G. Jung] (J. Nunes Brito \& M. Leal, Trads.; Título original: Lexikon der jungschen Grundbegriffe: Mit Originaltexten von C. G. Jung). São Paulo, Brasil: Loyola.

Harré, R. \& Lamb, R. (1983/1990a). Diccionario de psicología fisiológica y clínica (J. Fordito, Trad.; Título original: The encyclopedic dictionary of psychology). Barcelona, España: Paidós.

Harré, R. \& Lamb, R. (1983/1990b). Diccionario de psicología evolutiva y de la educación (L. Wolfson, Trad.; Título original: The encyclopedic dictionary of psychology). Barcelona, España: Paidós. 
Harré, R. \& Lamb, R. (1983/1991). Diccionario de etología y aprendizaje animal (J. Balderrama, Trad.; Título original: The encyclopedic dictionary of psychology). Barcelona, España: Paidós.

Harré, R. \& Lamb, R. (1983/1992). Diccionario de psicología social y de la personalidad (J. Piatigorsky, Trad.; Título original: The encyclopedic dictionary of psychology). Barcelona, España: Paidós.

Hinshelwood, R. D. (1989/1992a). Diccionario del pensamiento kleiniano (J. L. Etcheverry, Trad.; Título original: A dictionary of Kleinian thought). Buenos Aires, Argentina: Amorrortu.

Hinshelwood, R. D. (1989/1992b). Dicionário do pensamento kleiniano [Diccionario del pensamiento kleiniano] (J. O. de Aguiar Abreu, Trad.; Título original: A dictionary of Kleinian thought). Porto Alegre, Brasil: Artes Médicas.

Hospital Psiquiátrico de La Habana (1981). Primer tesauro cubano de psicología. La Habana, Cuba: Ministerio de Salud Pública.

Houdé, O., Kayser, D., Koenig, O., Proust, J. \& Rastier, F. (1998/2003). Diccionario de ciencias cognitivas: neurociencia, inteligencia artificial, lingüística y filosofía (C. R. Molinari Marotto, Trad.; Título original: Vocabulaire de sciences cognitives : Neuroscience, psychologie, intelligence artificielle, linguistique et philosophie). Buenos Aires, Argentina: Amorrortu.

Hurtado, J. G. G. M. (1991). Dicionário de psicomotricidade [Diccionario de psicomotricidad]. Porto Alegre, Brasil: Prodil.

Kahtuni, H. C. \& Sanches, G. P. (2009). Dicionário do pensamento de Sandór Ferenczi: uma contribuição à clínica psicanalítica contemporânea [Diccionario del pensamiento de Sándor Ferenczi: una contribución a la clínica psicoanalítica contemporánea]. São Paulo, Brasil: Campus/Fundação de Amparo à Pesquisa do Estado de São Paulo.

Kaufmann, P. (Dir.) (1993/1996a). Elementos para una enciclopedia del psicoanálisis: el aporte freudiano (J. Piatigorsky, Trad.; Título original: L'apport freudien : Éléments pour une encyclopédie de la psychanalyse). Buenos Aires, Argentina: Paidós.

Kaufmann, P. (1993/1996b). Dicionário enciclopédico de psicanálise: o legado de Freud e Lacan [Diccionario enciclopédico de psicoanálisis: el legado de Freud y Lacan] (V. Ribeiro \& M. L. Borges, Trads.; Título original: L'apport freudien : Éléments pour une encyclopédie de la psychanalyse). Rio de Janeiro, Brasil: Zahar.

Klappenbach, H. (2006). Periodización de la psicología en Argentina. Revista de Historia de la Psicología, 27(1), $109-164$.

Klappenbach, H. (2014). Acerca de la metodología de investigación en la historia de la psicología. Psykhe, 23(1), 1-12. https://doi.org/10.7764/psykhe.23.1.584

Klappenbach, H. A. \& Pavesi, P. (1994). Una historia de la psicología en Latinoamérica. Revista Latinoamericana de Psicología, $26,445-481$.

Lagache, D. (1967/1996). Razones e historia de esta obra. En J. Laplanche \& J. -B. Pontalis, Diccionario de psicoanálisis (11 ${ }^{a}$ Reimpresión; pp. IX-XII; F. Cervantes Gimeno, Trad.; Título original: Vocabulaire de la psychanalyse). Barcelona, España: Paidós.

Laplanche, J. \& Pontalis, J. -B. (1967/1979). Diccionario de psicoanálisis (2 ${ }^{a}$ Reimpresión; F. Cervantes Gimeno, Trad.; Título original: Vocabulaire de la psychanalyse). Barcelona, España: Labor.

Laplanche, J. \& Pontalis, J. -B. (1967/1988). Vocabulário da psicanálise [Vocabulario del psicoanálisis] (10ª ed.; P. Tamen, Trad.; Título original: Vocabulaire de la psychanalyse). São Paulo. Brasil: Martins Fontes.

Laplanche, J. \& Pontalis, J. -B. (1967/1996). Diccionario de psicoanálisis (11ª Reimpresión; F. Cervantes Gimeno, Trad.; Título original: Vocabulaire de la psychanalyse). Barcelona, España: Paidós.

Laplanche, J. \& Pontalis, J. -B. (1967/2001). Vocabulário da psicanálise [Vocabulario del psicoanálisis] (4ª ed.; P. Tamen, Trad.; Título original: Vocabulaire de la psychanalyse). São Paulo, Brasil: Martins Fontes.

León, R. (1979). En torno al 'diccionario de psicología' de Merani. Comportamiento, 2(2), 58-65.

Mankeliunas, M. V. (1959). Bibliografía. Revista Colombiana de Psicología, 4(2), 89-95.

Menegazzo, C. M. (1992/1995). Introdução [Introducción]. En C. M. Menegazzo, M. A. Tomasini \& M. M. Zuretti (Eds.), Dicionário de psicodrama e sociodrama [Diccionario de psicodrama y sociodrama] (pp. 7-11; M. Lopes, M. Carbajal \& V., Trads.; Título original: Diccionario de psicodrama y sociodrama). São Paulo, Brasil: Ágora.

Menezes, D. (1933). Psicologia [Psicología]. Porto Alegre, Brasil: Globo.

Menezes, D. (1935a). Pedagogia [Pedagogía]. Porto Alegre, Brasil: Globo.

Menezes, D. (1935b). Dicionário psico-pedagógico [Diccionario psico-pedagógico]. São Paulo, Brasil: Companhia Editora Nacional.

Merani, A. (1979). Diccionario de psicología (3 ed.). Barcelona, España: Grijalbo.

Merani, A. (1982). Diccionario de pedagogía. Barcelona, España: Grijalbo.

Merani, A. (1983). Diccionario de psicología y psiquiatría infantil. Barcelona, España: Grijalbo.

Mercante, V. (1916). Prólogo. En F. Rodríguez, Diccionario de los términos técnicos usados en psicología (pp. V-VI). Buenos Aires, Argentina: Cabut.

Mira y López, E. (1957/1964). Prólogo. En H. Pierón, Lexicón Kapelusz Psicología (pp. IX-X; L. Alfonso, Trad.; Título original: Vocabulaire de la psychologie). Buenos Aires, Argentina: Kapelusz.

Mora, F. \& Sanguinetti, A. M. (1994). Diccionario de neurociencias. Madrid, España: Alianza.

Moreira Leite, D. (2009). Estudos em psicologia [Estudios de psicología]. São Paulo, Brasil: Universidade Estadual Paulista Júlio de Mesquita Filho.

Morel, H. V. \& Moral, J. D. (1986). Diccionario de parapsicología (3 ${ }^{\text {a }}$ Reimpresión). Buenos Aires, Argentina: Kier.

Novaes, M. H. \& Martins, O. (1968). Glossário de termos referentes aos testes e medidas psicológicas [Glosario de términos referentes a los test y medidas psicológicas]. Rio de Janeiro, Brasil: Fundação Getúlio Vargas.

Novaes, M. H. \& Martins, O. (1969). Glossário de termos referentes aos testes e medidas psicológicas [Glosario de términos referentes a los test y medidas psicológicas]. Arquivos Brasileiros de Psicologia Aplicada, 21(1), 102-124.

Olazo García, J. L. (2003). El diccionario de psicología y sexología. Puebla, México: Siena.

Oñativia, O. (1928/1951). Introducción. En H. B. English, Diccionario manual de psicología (pp. IX-XIII; O. Oñativia, Trad.; Título original: A student's dictionary of psychological terms). Buenos Aires, Argentina: El Ateneo.

Paula, J. (1970). Dicionário de parapsicologia, metapsíquica e espiritismo [Diccionario de parapsicología, metapsíquica y espiritismo]. São Paulo, Brasil: Banco Cultural Brasileiro.

Pereira, A. (1981). Dicionário da vida sexual [Diccionario de la vida sexual]. São Paulo, Brasil: Abril Cultural.

Pichon-Rivière, J. (1995). Diccionario de términos y conceptos de psicología y psicología social. Buenos Aires, Argentina: Nueva Visión.

Pieri, P. F. (1992/2002). Dicionário junguiano [Diccionario junguiano] (I. Storniolo, Trad.; Título original: Dizionario junghiano). Petrópolis, Brasil: Vozes.

Pierón, H. (1957/1964a). Prefacio. En H. Pierón, Lexicón Kapelusz Psicología (2ª ed., pp. XV-XVII; L. Alfonso, Trad.; Título original: Vocabulaire de la psychologie). Buenos Aires, Argentina: Kapelusz. 
Pierón, H. (1957/1964b). Prefacio. En H. Pierón, Lexicón Kapelusz Psicología (pp. XI-XIII; L. Alfonso, Trad.; Título original: Vocabulaire de la psychologie). Buenos Aires, Argentina: Kapelusz.

Pierón, H. (1957/1977). Dicionário de psicologia [Diccionario de psicología] (5a ed.; D. de Barros Cullinan, Trad.; Título original: Vocabulaire de la psychologie). Porto Alegre, Brasil: Globo.

Pierón, H. (1968/1993). Dicionário de psicologia [Diccionario de psicología] (8ª ed.; D. de Barros Cullinan, Trad.; Título original: Vocabulaire de la psychologie). São Paulo, Brasil: Globo.

Rambaut, L. (2002). Diccionario crítico de psicología social: según la teoría del doctor Enrique Pichn-Rivière. Buenos Aires, Argentina: Autor.

Rascovsky, A. \& Rosenthal, L. (1947). La formación psicoanalítica: consideraciones sobre el desarrollo del movimiento psicoanalítico en América Latina. Revista de Psicoanálisis, 4, 646-663.

Rodrigues Teixeira Jr., R. \& Oliveira de Souza, M. A. (2006). Vocabulário de análise do comportamento: um manual de consulta para termos usados na área [Vocabulario de análisis del comportamiento: un manual de consulta para términos utilizados en el área]. São Paulo, Brasil: ESETec.

Rodríguez, F. (1916). Diccionario de los términos técnicos usados en psicología. Buenos Aires, Argentina: Cabut.

Rossi, L. (Ed.) (1994). Psicología en Argentina. Capítulos olvidados de una historia reciente. Buenos Aires, Argentina: Tekné.

Roudinesco, E. \& Plon, M. (1997/1998a). Advertencia. En E. Roudinesco \& M. Plon, Diccionario de psicoanálisis (pp. 9-12; J. Piatigorsky, Trad.; Título original: Dictionnaire de la psychanalyse). Buenos Aires, Argentina: Paidós.

Roudinesco, E. \& Plon, M. (1997/1998b). Diccionario de psicoanálisis (J. Piatigorsky, Trad.; Título original: Dictionnaire de la psychanalyse). Buenos Aires, Argentina: Paidós.

Roudinesco, E. \& Plon, M. (1997/1998c). Dicionário de psicanálise [Diccionario de psicoanálisis] (V. Ribeiro \& L. Magalhães, Trads.; Título original: Dictionnaire de la psychanalyse). Rio de Janeiro, Brasil: Zahar.

Rovaletti, M. L. (1998). Panorama psicológico argentino: antecedentes, constitución, institucionalización y profesionalización de la psicología. Cuyo: Anuario de Filosofía Argentina y Americana, 15, 79-108.

Rycroft, C. (1968/1976). Diccionario de psicoanálisis (B. Corsd, Trad.; Título original: A critical dictionary of psychoanalysis). Buenos Aires, Argentina: Paidós.

Samuels, A., Shorter, B. \& Plaut, F. (1986/1988). Dicionário crítico de análise junguiana [Diccionario crítico de análisis junguiano] (P. Ratis e Silva, Trad.; Título original: A critical dictionary of Jungian analysis). Rio de Janeiro, Brasil: Imago.

Schneider, E. (1955). Normas para unificação de uma terminologia básica em psicotécnica [Normas para la unificación de una terminología básica en psicotecnia]. Arquivos Brasileiros de Psicotécnica, 7(4), 17-22.

Sharp, D. (1991/1994). Lexicon junguiano: compendio de términos y conceptos de la psicología de Carl Gustav Jung (E. Olivos, Trad.; Título original: Jung lexicon: A primer of terms \& concepts). Santiago, Chile: Cuatro Vientos.

Sillamy, N. (1967/1974). Diccionario de la psicología (4 ${ }^{\mathrm{a}}$ ed.) [J. Ferrer Aleu, Trad.; Título original: Dictionnaire de la psychologie]. Barcelona, España: Plaza \& Janés.

Stingo, N. R., Toro Martínez, E., Epiño, G. \& Zazzi, M. C. (2006). Diccionario de psiquiatría y psicología forense. Buenos Aires, Argentina: Polemos. Székely, L. C. B. (1950). Diccionario enciclopédico de la psique. Buenos Aires, Argentina: Claridad.

Székely, L. C. B. (1958). Diccionario enciclopédico de la psique (2a ed.). Buenos Aires, Argentina: Claridad.

Székely, L. C. B. (2010). Diccionario de psicología. Buenos Aires, Argentina: Claridad.

Toro, J. P. \& Villegas, J. F. (Eds.) (2001). Problemas centrales para la formación académica y el entrenamiento profesional del psicólogo en las Américas (Vol. I). Buenos Aires, Argentina: Sociedad Interamericana de Psicología.

Valls, J. L. (1995). Diccionario freudiano. Madrid, España: Julián Yébenes.

Valmor, D. (1966). Diccionario de psicología y psicoanálisis. Buenos Aires, Argentina: Schapire.

Villegas, J., Marassi, P. \& Toro, J. P. (Eds.) (2003a). Problemas centrales para la formación académica y el entrenamiento profesional del psicólogo en las Américas (Vol. II). Santiago, Chile: Sociedad Interamericana de Psicología.

Villegas, J., Marassi, P. \& Toro, J. P. (Eds.) (2003b). Problemas centrales para la formación académica y el entrenamiento profesional del psicólogo en las Américas (Vol. III). Santiago, Chile: Sociedad Interamericana de Psicología.

Vinaccia, S. (1978). Historia de la terapia del comportamiento en Latinoamérica. Aprendizaje y Comportamiento, 1, 11-20.

Virel, A. (1977/1985). Vocabulario de las psicoterapias (R. Núñez, Trad.; Título original: Vocabulaire des psychothérapies). Barcelona, España: Gedisa.

Warren, H. C. (Comp.) (1934/1998). Diccionario de psicología (3a ed.; E. Ímaz, A. Alatorre \& L. Alaminos, Trads.; Título original: Dictionary of psychology). México DF, México: Fondo de Cultura Económica.

Wolman, B. B. (Ed.) (1975). Dictionary of behavioral science (1a Reimpresión). New York, NY: Macmillan.

Wolman, B. B. (Ed.) (1973/1987). Diccionario de ciencias de la conducta (1ª Reimpresión; M. Sandoval Pineda \& E. Ribes Iñesta, Trads.; Título original: Dictionary of behavioral science). México DF, México: Trillas.

Zimerman, D. (2001). Vocabulário contemporâneo de psicanálise [Vocabulario contemporáneo de psicoanálisis]. Porto Alegre, Brasil: Artmed.

Fecha de recepción: Mayo de 2016.

Fecha de aceptación: Octubre de 2017. 